APL/JHU

$\frac{\text { ANSP-M-13 }}{2}$

EROA/DNRA 3060-13

JULY 1976

Copy No. $\quad \mathbf{5}$

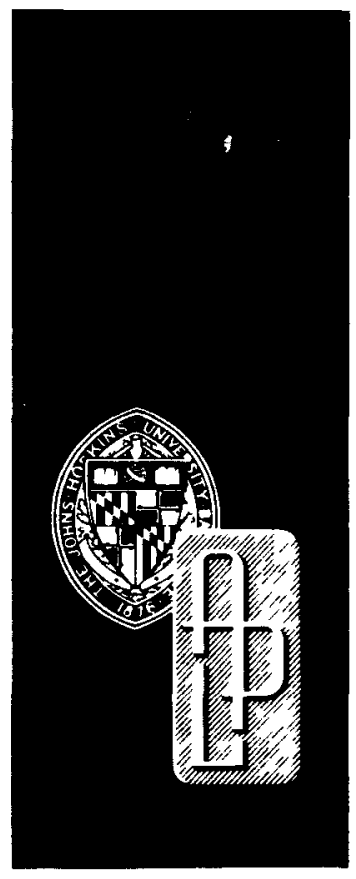

Aerospace Nuclear Safety Program

\title{
STRESS ANALYSIS OF
}

DISCONNECTED STRUCTURES IN CONTACT THROUGH FINITE

ELEMENT GAPS

by J. T. STADTER and R. O. WEISS

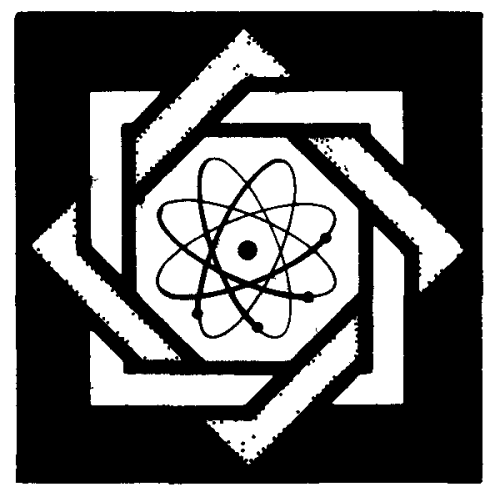

THE JOHNS HOPKINS UNIVERSITY - APPLIED PHYSICS LABORATORY MASTER 



\section{DISCLAIMER}

Portions of this document may be illegible in electronic image products. Images are produced from the best available original document. 


\section{DISCLAIMER}

This report was prepared as an account of work sponsored by an agency of the United States Government. Neither the United States Government nor any agency Thereof, nor any of their employees, makes any warranty, express or implied, or assumes any legal liability or responsibility for the accuracy, completeness, or usefulness of any information, apparatus, product, or process disclosed, or represents that its use would not infringe privately owned rights. Reference herein to any specific commercial product, process, or service by trade name, trademark, manufacturer, or otherwise does not necessarily constitute or imply its endorsement, recommendation, or favoring by the United States Government or any agency thereof. The views and opinions of authors expressed herein do not necessarily state or reflect those of the United States Government or any agency thereof. 


\section{APL/JHU}

ANSP-M-13

ERDA/DNRA 3060-13

JULY 1976
Aerospace Nuclear Safety Program

\section{STRESS ANALYSIS OF DISCONNECTED STRUCTURES IN CONTACT THROUGH FINITE ELEMENT GAPS}

by J. T. STADTER and R. O. WEISS

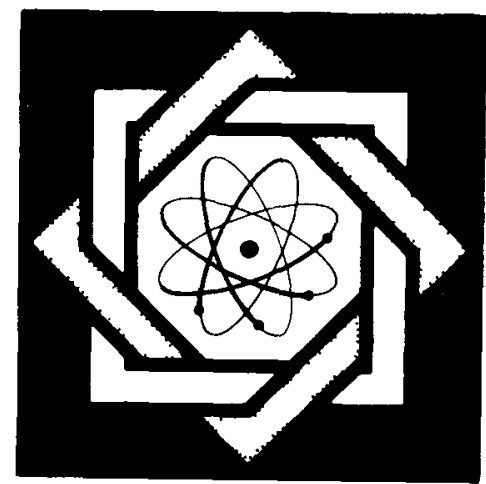

THE JOHNS HOPKINS UNIVERSITY - APPLIED PHYSICS LABORATORY Johns Hopkıns Road o Laurel, Maryland o 20810 


\section{FOREWORD}

The work reported herein was conducted by the Aeronautics Division of the Applied Physics Laboratory for the Energy Research and Development Administration, Division of Nuclear Research and Applications. Activities of the Aeronautics Division are under the $>$ general supervision of $\mathrm{Dr}$. William H. Avery. The Project Engineer for the Aerospace Nuclear Safety Program is James C. Hagan. 


\section{ABSTRACT}

A numerical procedure is presented for analyzing thermal stress problems of disconnected structures in contact across separations or gaps. The new procedure is called SAASGAPS---it is an adaptation of the basic SAAS III computer program. The SAAS program uses the finite element method and allows analyses of plane and axisymmetric bodies with temperature dependent material properties, subject to thermal and mechanical loads. A secant modulus approach with a bilinear stress-strain curve is used for elastic-plastic problems.

The SAASGAPS version contains all of the features of the original SAAS program. A special gap element is used together with a stress invariance principle to model the contact process. This report describes the iterative procedure implemented in SAASGAPS. Results are discussed for five problems involving frictionless contact. Two of these problems are associated with the thermal stress analysis of the heat shield for the Multi-Hundred Watt Radioisotope Thermoelectric Generator. Input instructions for the program are described in an appendix. 
I. INTRODUCTION AND SUMMARY 1

II. A GENERAL APPROACH TO STRUCTURES CONTAINING GAPS 3

III. SAMPLE PROBLEMS 11

PROBLEM (1) UNIFORM LOAD APPLIED TO

UNRESTRAINED STRUCTURE

PROBLEM (2) CONTACT ACROSS A GAP DUE TO THERMAL EXPANSION

PROBLEM (3) BENDING WITH CONTACT UNDER A UNIFORM LATERAL LOAD

IV. MHW AEROSHELL GAP CLOSURE PROBLEMS

PROBLEM (1) SIDE-ON REENTRY WITH THERMAL AND MECHANICAL LOADING

PROBLEM (2) END-ON REENTRY WITH THERMAL LOADING

$\begin{array}{ll}\text { V. CONCLUDING REMARKS } & 48\end{array}$

$\begin{array}{lr}\text { VI. REFERENCES } & 49\end{array}$

$\begin{array}{lll}\text { APPENDIX A. SAASGAPS INPUT INSTRUCTIONS } & 51\end{array}$

$\begin{array}{ll}\text { APPENDIX B. SAASGAPS OUTPUT } & 54\end{array}$ 
TABLE I GAP CLOSURE TEST PROBLEM: 1 UNIFORM LOAD APPLIED TO AN UNRESTRAINED MODEL

TABLE II GAP CLOSURE TEST PROBLEM: 2 CONTACT ACROSS A GAP DUE TO THERMAL EXPANSION

TABLE III GAP CLOSURE TEST PROBLEM: 3 BEAM BENDING WITH UNIFORM LOAD

a. Case 1, Elastic Solution

b. Case 2, E1astic Solution with Secondary Modulus

c. Case 3, Elastic-Plastic Solution

TABLE IV RETAINER RING/GAP/AEROSHELL PROBLEM

TABLE V END CAP/AEROSHELL BARREL CONTACT PROBLEM 
PAGE NO.

FIGURE 1: REGIONS SEPARATED BY GAPS 4

FIGURE 2: $\quad$ STRESS INVARIANCE FOR GAP CLOSURE 7

FIGURE 3: MODELS USED IN SAMPLE CLOSURE PROBLEMS

FIGURE 4a: BEAM BENDING WITH UNIFORM LOAD - CASE 1

b: BEAM BENDING WITH UNIFORM LOAD - CASE 2

c: BEAM BENDING WITH UNIFORM LOAD - CASE 3

FIGURE 5: THE MHW HEAT SOURCE

FIGURE 6: HEAT SHIELD LOAD DISTRIBUTION, SIDE-ON REENTRY 27

FIGURE 7: FINITE ELEMENT MODEL FOR SIDE-ON STABLE REENTRY ANALYSIS

FIGURE 8: EXPANDED WALL REPRESENTATION OF FINITE ELEMENT MODEL

FIGURE 9: TEMPERATURE CONTOURS FOR SIDE-ON REENTRY ANALYSIS 31

FIGURE 10: CONTOURS OF MAXIMUM STRESS IN THE PLANE FOR SIDE-ON REENTRY

FIGURE 11: CONTOURS OF HOOP STRESS FOR SIDE-ON REENTRY 33

FIGURE 12: RETAINER RING/GAP/AEROSHELL PROBLEM -

ALL GAP ELEMENTS $\quad 36$

FIGURE 13: RETAINER RING/GAP/AEROSHELL PROBLEM -

CLOSED GAP ELEMENTS

FIGURE 14: FINITE ELEMENT MODEL FOR END-ON STABLE REENTRY ANALYSIS

FIGURE 15: END CAP/AEROSHELL BARREL GAP ELEMENTS 40

FIGURE 16: TEMPERATURE CONTOURS FOR END-ON REENTRY ANALYSIS 42

FIGURE 17: CONTOURS OF MAXIMUM STRESS IN THE PLANE FOR ENDON REENTRY 43

FIGURE 18: CONTOURS OF HOOP STRESS FOR END-ON REENTRY 44

FIGURE 19: STRESS INVARIANCE WITH EXTRAPOLATION FOR GAP CLOSURE 


\section{INTRODUCTION AND SUMMARY}

The finite element method is used extensively in structural analysis. When implemented on present-day computers, the method provides a problemsolving capability which admits many factors normally neglected in simple analyses. At the Applied Physics Laboratory (APL), the SAAS III computer program (Ref. 1) has been used for the stress analysis of the Multi-Hundred Watt Radioisotope Thermoelectric Generator (MHW-RTG) heat shield. This finite element program allows analyses of plane and axisymmetric bodies subject to thermal or mechanical loads and having temperature-dependent orthotropic material properties. The program is iterative, using a bilinear stress-strain curve together with a secant modulus formulation to analyze elastic-plastic problems. The numerical capabilities of the SAAS III program have, in most cases, been adequate for thermostructural evaluation of the MHW-RTG heat shield. Current heat shield designs have gaps separating the various structural components. These gaps have been included in the finite element models of the heat shield. As long as rigid body motion was not allowed in the problem formulation, the presence of small separations in the model was not prohibitive to the SAAS program. Of course, the deflections could not be such that one region "displaced over" the otner. It soon became apparent that the more general nonlinear problem involving limited rigid body movement across a gap, with subsequent contact of disconnected regions, was a problem that the SAAS III program could not address. Therefore, the need for a new procedure, capable of analyzing contact and interference-type problems, was indicated. 
Before the widespread use of computers, contact and interference analyses were limited primarily to a Hertz-type solution. Examples of the Hertz contact theory are discussed by Lubkin, in Section 42 of Ref. 2 which also provides a good review of work published prior to 1962. More recent1y, special programing techniques have been used to formulate simple elastic contact problems (Refs. 3-5). The overall complexity of the contact problem has been discussed in a recent survey paper by Newman (Ref. 6). Within the last ten years, efforts have been made to include contact within the scope of finite element procedures (Refs. 7-10). In these finite element formulations, contact forces are transmitted at nodal points when disconnected bodies come together.

Rather than adopt a totally new finite element procedure, we have chosen to use the SAAS III program as the basis for developing a capability for structural contact problems. The new version of SAAS, called SAASGAPS, uses gap elements with appropriate material property specifications together with a "stress invariance" principle to describe the frictionless contact process. Contact is determined by the amount of deformation of these gap elements.

This report describes the procedure implemented in SAASGAPS. Resu1ts are presented for three sample gap closure problems which illustrate the general capability of the program. Then, two contact problems associated with the MHW-RTG heat shield are considered. Various difficulties associated with these analyses are brought out in the discussion of the results. The input instructions for the SAASGAPS program are given in Appendix A. 
THE JOHNS HOPKINS UNIVERSITY APPLIED PHYSICS LABORATORY LAUREL MARYLAND

\section{A GENERAL APPROACH TO STRUCTURES CONTAINING GAPS}

It is not difficult to imagine situations in which two or more structural members, initially separated but in close proximity to each other, come into contact under load. Any assembled unit consisting of a number of parts has the potential for such behavior.

Consider two such disjoint regions (Fig. 1) which have been modelled for a finite element analysis. The open area or "gap" between the two bodies is also subdivided into elements such that a continuous model is constructed. However, the gap elements are fictitious in that they offer no resistance to the relative motions of regions $A$ and $B$ except to prevent those two regions from over lapping under the applied load. That is to say, due to the applied point loads $F$, distributed loads $P$ and temperatures $T$, each region is free to deform such that a portion of their boundaries may contact but not cross. We emphasize that because of the way the contact problem is being posed, a certain amount of rigid body motion is included in the total displacement vector.

In order to describe the procedure for analyzing structures containing gaps, we focus attention on gap element $i$ in Fig. 1 and define a local set of orthogonal M-N axes for this element, where $M$ is the direction across the gap. The element will "open" or "close" depending upon the behavior of regions A and B. Gap opening is indicated when a tensile normal strain, $\epsilon_{M}$, develops. When this occurs, the element should not retard the motion of regions $A$ and $B$, consequent ly the gap modulus $E_{M}$ must be negligible and the normal stress $\sigma_{M}$ should be small in comparison to the stresses that exist in regions $A$ and $B$. On the other hand, the gap closes when $\varepsilon_{M}$ becomes negative (compressive) and closes fully when $\varepsilon_{M}$ is $-100 \%$ indicating that the regions $A$ and $B$ have come into 

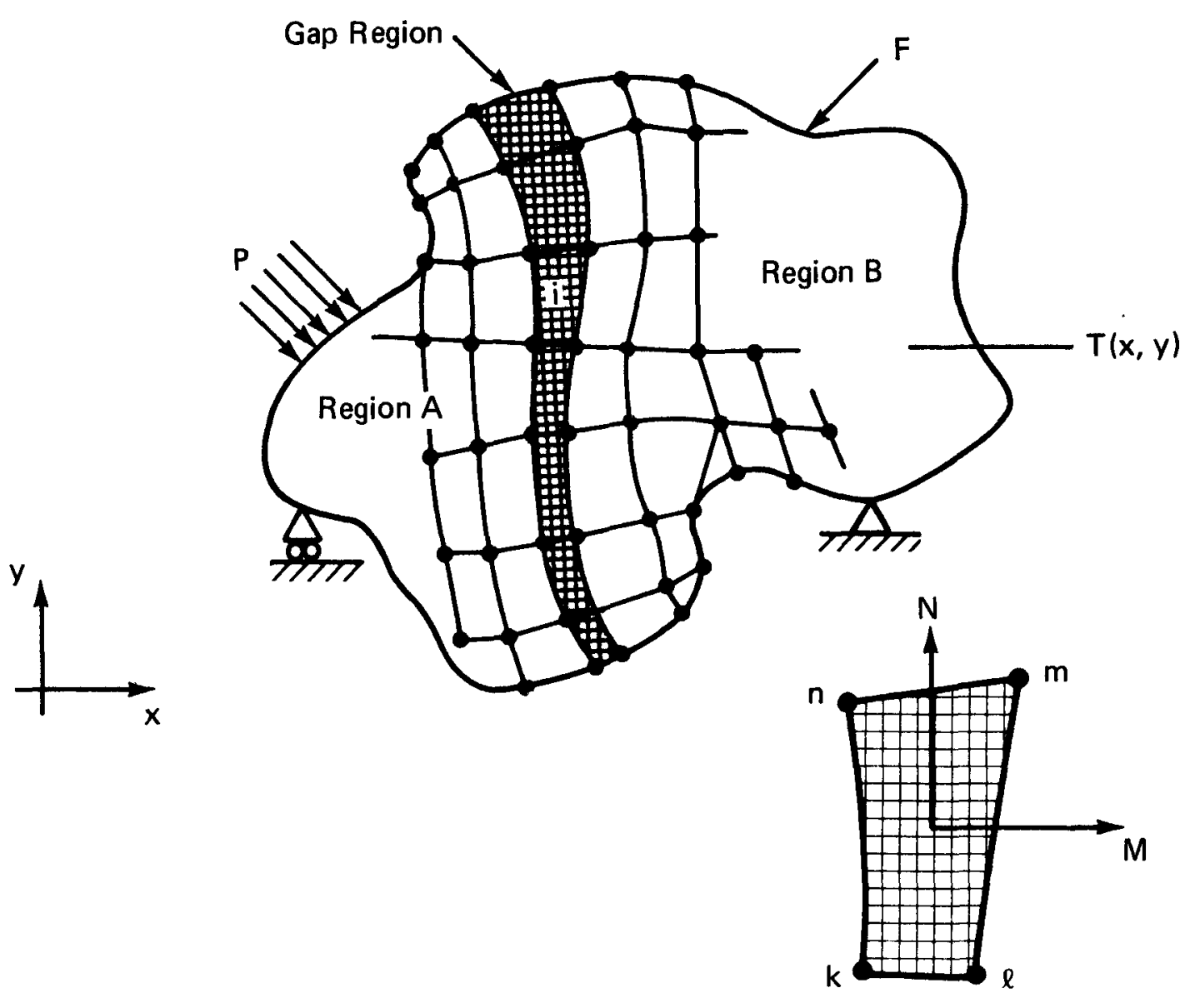

Gap Element i

Fig. 1 Regions Separated by Gaps 
THE JOHNS HOPKINS UNIVERSITY APPLIED PHYSICS LABORATORY

LAUREL MARYLAND

contact. Obviously, a normal gap strain of less than $-100 \%$ is unacceptable since this implies that one boundary has displaced "beyond" the other.

The basic scheme of our procedure is rather simple - we adjust the moduli of the gap elements so that those which either open or partially close have a negligibly small modulus (so that relative motion of the two regions is not impeded). Those gap elements which fully close have a modulus sufficiently large to allow contact of neighboring boundaries while preventing overlapping of those boundaries. The implementation of this scheme seems equally simple - decrease the modulus of each gap element until that element either is fully closed (at which point the modulus is held fixed) or has essentially zero modulus.

The numerical procedure relies on an analogy with the strain invariance principle employed for plasticity calculations. We assume that the normal gap stress, $\sigma_{M}$, will not change very much due to gap closure when compared with a "suitable" initial solution for the problem. We define the initial solution as being suitable when the initial gap moduli are such that some of the gap strains are the order of $-100 \%$ or less (i.e., closure is indicated). The stress invariance principle applied here is analogous to the strain invariance principle used in plasticity theory (Ref. 11) which states that the total strains do not change very much due to plastic deformation. In applying the strain invariance principle, an iterative process is evolved which allows an estimate of the plastic strain components to be obtained from the stress-strain curve using the most recent value of the total strain. 
The stress invariance concept used for those gaps in compression is illustrated in Fig. 2 for a representative gap element i. A suitable initial solution is obtained with a normal gap modulus $E_{1}$ such that a closure* of greater than $100 \%$ has occurred in gap element $i$. Employing invariance we have

$$
\sigma_{M_{1}}=E_{1} \varepsilon_{M_{1}}=E_{2} \epsilon_{\text {gap }}
$$

where $\epsilon_{\text {gap }}=-1.0$ for contact. This equation implies that the normal gap stress will not change in the second iteration. For the next solution we use $E_{2}$ obtained from the above equation for gap element $i$. However, since the behavior in one gap element is dependent upon the adjustments being made in other elements, the second solution will, in general, not satisfy the contact requirement. The second solution must lie on the stress-strain line with slope $E_{2}$. Notice that the iteration process being described is, for a given problem, well behaved if an increase in gap stiffness results in a decrease in closure. Therefore, after $\mathrm{K}$ iterations the gap modulus to be used in the $(\mathrm{K}+1)-\mathrm{st}$ iteration for element $i$ is given by

$$
E_{K+1}^{i}=-E_{K}^{i} \varepsilon_{M_{K}}^{i}
$$

\footnotetext{
${ }^{*}$ Closure (in \%) is defined to be $-100 \times \epsilon_{M}$ where $\epsilon_{M}$ is a negative gap strain.
} 


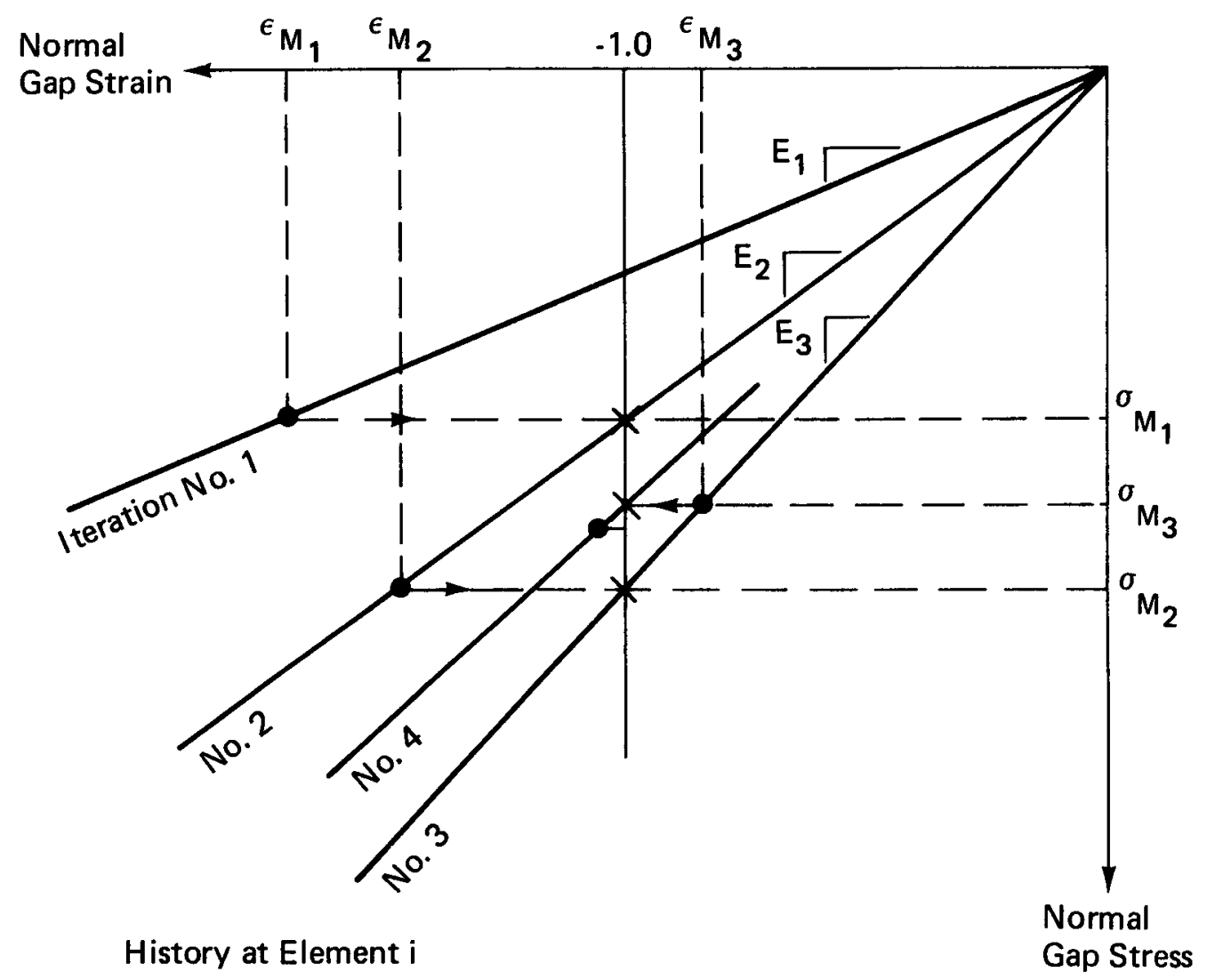

Fig. 2 Stress Invariance for Gap Closure 
Although this is a simple relationship for computing the modulus of a compressed gap element at each step after the first, in practice the numerical scheme is more complex. The reasons for this are the sensitivity of the process to the particular geometry being analyzed and the necessity of limiting the rigid body motions so that elements do not overlap. The former aspect wil1 be discussed in Section IV. The restriction on rigid body motion is achieved initially by selecting a gap modulus which is small enough to permit some gap closure but large enough to limit rigid body motions. The "solution" is attained when all gap elements have a normal strain $\epsilon_{M} \geq-1.00$ and those elements with $\varepsilon_{M}>-1.00$ have negligible stiffness.

The procedure described above suffers from a lack of generality in the manner in which the gap tensile modulus is relaxed. This relaxation is necessary in order that no region be artificially constrained - relative motion is inherently part of the problem. The manner in which the rigid body motion is controlled depends on the geometry and load levels of the particular problem being analyzed. We detail below the procedure which proved most satisfactory.

(a) For the initial solution, the normal moduli, $E_{M}$ (and $E_{N}$ ) for all gap elements are set to a value specified through input. The initial value should be small enough to produce a suitable solution. Although the initial value will normally be problem dependent, a value between 20 and 75 psi has proven to be adequate for the problems discussed in this report. 
(b) In subsequent iterations the moduli of gap elements which are in compression are determined by the stress invariance principle described above (Eq. 1). The moduli of gap elements in tension are controlled by the user through a schedule of decreasing values, terminating with a low value (say 1 psi). This tensile gap modulus schedule will control the convergence of the gap closure process and therefore should be gradual enough to permit effective adjustments in the moduli of the compressed gaps. Again, a successful tensile modulus reduction schedule will depend on the problem under study. A relative reduction in tensile modulus of from $1 / 2$ to $3 / 4$ has 1 ed to converged solutions for those problems to be discussed here.

(c) Within the program for all gap elements, Poisson's ratio is set to zero and the transverse gap modulus $\left(E_{N}\right)$ is set to the current value of the tensile gap modulus $\left(E_{M}\right)$. A finite value for $E_{N}$ tends to provide additional gap element rigidity during the initial iterations, resulting in better overall convergence characteristics.

(d) The basic algorthim for gap closure makes corrections based on the current solution and therefore does not anticipate the changes that will be produced by the tensile modulus scheduled in the next iterated solution. To alleviate this situation to some degree, the incremental modulus reduction occurring in the tensile gaps is added to the modulus of all compressed gaps for the next iteration. This additional increment to the modulus of compressed gaps helps to limit the changes in gap strain (for compressed gaps) while the moduli of gaps in tension are relaxing. 
(e) Convergence is achieved when all tensile gap elements have the smallest value of modulus in the reduction schedule (which should be essentially zero) and no compressive gap element is overclosed. In the computer program this latter criterion is applied with a tolerance of $5 \%$ so that all gap elements in compression must have a normal strain $\epsilon_{M}>-1.05$

In the following section, three samples are given to illustrate the analysis procedure for gap closure problems. The input instructions for the SAASGAPS program are described in the appendix. 


\section{SAMPLE PROBLEMS}

Three simple problems have been devised to illustrate the behavior of the gap closure algorithm. Fig. 3 shows the two models used for the problems. Mode1 A is a coarse mesh consisting of structural elements numbered 1 through 9 and gap elements, 10 through 20. In total, this model has 20 elements and 34 nodal points. By comparison, model $B$ is much finer, consisting of 98 elements (including 26 gap elements) and 124 nodes. A p1ane stress specification was used in all three of these problems.

\section{Problem (1) - Uniform load applied to unrestrained structure}

The first problem involves the use of model A with a uniform pressure load of 1000 psi acting in the Z-direction on the top surface of elements 1 through 9, (nodes 2 to 11 ). The structure is not restrained in any way since no constraints are specified for the nodes of elements 1 through 9 . Al1 gap elements have a width of 0.009 inches and an initial elastic modulus of 100 psi. A modulus $E=10^{6}$ psi was used for the structural elements. The loading system should close the gaps and result in a compressive stress of 1000 psi in the body. The vertical displacement of nodes 25-34 was set to zero, thereby specifying a rigid wall. The object of this problem is to demonstrate a uniform contact with the wall through closure of gap elements 11-19. Table I illustrates the behavior of this problem. The initial gap stiffness of 100 psi was selected because this value was small enough in comparison with the structural stiffness of $10^{6}$ to allow contact across the gap elements. Indeed, as shown in Table I, a rigid body displacement of 10 gap widths resulted. However, the following iterations show that recovery is quick so that convergence is complete by the third iteration. The gap elements are completely closed (99\%) and a compressive stress of 1000 psi exists in the structural elements. 
Model A

Gap Elements Nos. 10-20

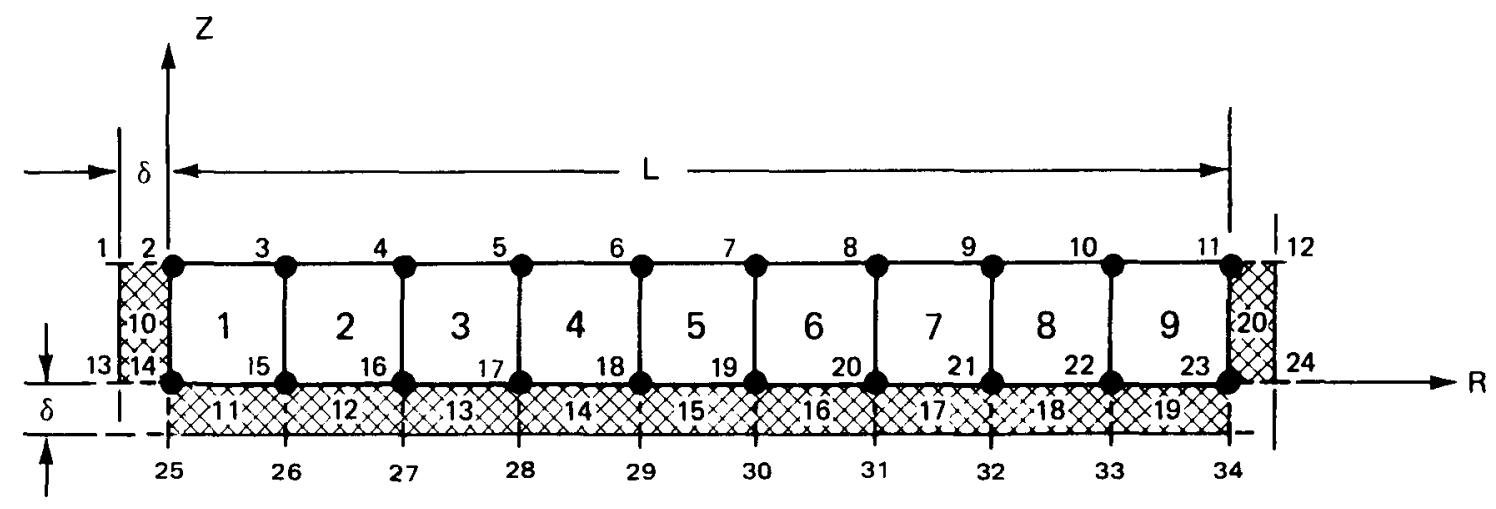

Model B

Gap Elements $\sim$ Nos. 1, 20, 21, 40, 41, 60, 61, 80, 81-98

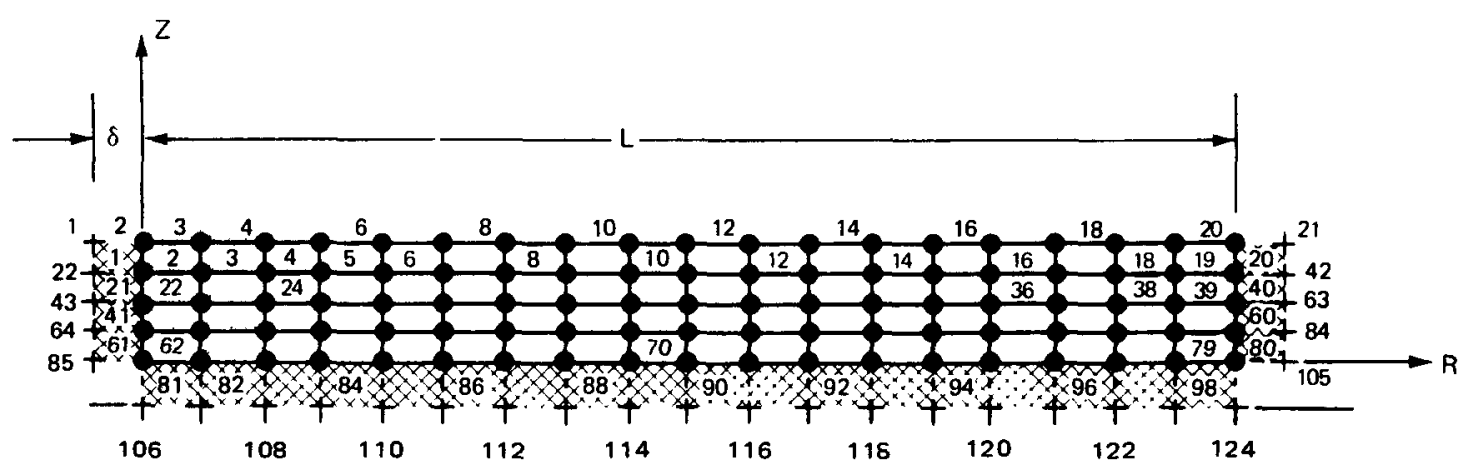

Fig. 3 Models Used in Sample Closure Problems 
Table I

Gap Closure Test Problem: 1

Uniform Load Applied to an

Unrestrained Model

\begin{tabular}{|c|c|c|}
\hline $\begin{array}{c}\text { Iteration } \\
\text { No. }\end{array}$ & $\begin{array}{c}\text { Gap } \\
\text { Modulus } \\
\text { (psi) }\end{array}$ & $\begin{array}{c}\text { Gap } \\
\text { Closure } \\
(\%)\end{array}$ \\
\hline 1 & $100.0^{*}$ & 1000.0 \\
\hline 2 & 1111.1 & 90.0 \\
3 & 1010.1 & 99.01 \\
4 & 1010.1 & 99.00 \\
\hline
\end{tabular}

${ }^{\dagger}$ Gap Elements No. 11-19 in Model A

*Initial Input Value 


\section{Problem (2) - Contact across a gap due to thermal expansion}

For the second problem, model A in Fig. 3 was again employed. This time nodes 2 and 14 of the body and 12 and 24 of the wall are constrained against horizontal movement and the model is subjected to a uniform increase in temperature. Three possibilities exist: (i) the free thermal growth is less than the gap width of element 20 , (ii) gap element 20 just closes completely, or (iii) the cumulative thermal growth of the structural elements is greater than the gap size will allow. The first two possibilities involve a stress free condition. We examine the last possibility more closely.

It is a simple matter to show that the unrestrained displacement of node 11 (and 23) is given by

$$
\mathrm{U}_{\mathrm{R}}=\alpha \mathrm{TL}
$$

where $\alpha$ is the coefficient of thermal expansion and $T$ is the total rise in temperature, $T=T_{0}+\Delta T$. Here $T_{0}$ is that temperature rise that is required to close the gap $\left(\mathrm{T}_{0}=\delta / \alpha \mathrm{L}\right)$ while the thermal growth due to the remaining temperature rise $\Delta T$ is constrained and results in a compressive stress equal to $\alpha \mathrm{E} \Delta \mathrm{T}$. If the following values are adopted:

$$
\begin{aligned}
& E=10^{6} \mathrm{psi}, \alpha=10^{-5} \mathrm{in} / \mathrm{in}^{\circ} \mathrm{F}, \\
& \mathrm{L}=9 \mathrm{in}, \delta_{20}=0.009 \mathrm{in.},(\mathrm{g} \text { ap width of element } 20 \text { ) } \\
& \mathrm{T}=1100^{\circ} \mathrm{F},
\end{aligned}
$$

then the gap is closed and a compressive stress of 10,000 psi wi11 occur in elements 1 through 9. Table II shows the results of applying the gap closure algorithm to this problem. Convergence has occurred in 5 iterations for an initial gap modulus of 100 psi. 
Table II

Gap Closure Test Problem: 2

Contact Across a Gap Due

to Thermal Expansion

\begin{tabular}{|c|c|c|c|}
\hline $\begin{array}{c}\text { Iteration } \\
\text { No. }\end{array}$ & $\begin{array}{c}\text { Gap } \\
\text { Modulus } \\
\text { (psi) }\end{array}$ & $\begin{array}{c}\sigma_{\mathbf{R}} \\
(\mathrm{psi})\end{array}$ & $\begin{array}{c}\text { Gap } \\
\text { Closure } \\
(\%)\end{array}$ \\
\hline 1 & $100.0^{*}$ & -1000.0 & 1000.2 \\
2 & 1111.3 & -5790.0 & 521.0 \\
3 & 6432.9 & -9520.0 & 148.0 \\
4 & 9616.8 & -9964.0 & 103.6 \\
5 & 10064.4 & -10006.0 & 99.4 \\
\hline
\end{tabular}

${ }^{\dagger}$ Gap Element No. 20 in Model A

*Initial Input Value 
THE JOHNS HOPKINS UNIVERSITY APPLIED PHYSICS LABORATORY

LaUREL MaRYLANO

Problem (3) - Bending with contact under a uniform lateral load

As a final sample problem, we consider a simply supported beam with a distributed load of $\mathrm{p}$ 1bs./in. applied on the upper surface in the negative $\mathrm{Z}$ direction. The maximum deflection occurs at center span and is given by (Ref. 12)

$$
\mathrm{U}_{Z}=-\frac{5 \mathrm{p}(2 \mathrm{~L})^{4}}{384 \mathrm{EI}}
$$

where $\mathrm{L}$ is the half span and $I$ is the moment of inertia of the cross section. To analyze this problem numerically, we use model A in Fig. 3 with the Z-axis as a line of symmetry $\left(U_{R}=0\right.$ at nodes 2 and 14). To simulate the simple support, we require the vertical displacement at node 23 to be zero. In addition, nodes 25 through 34 are fixed in space to represent a rigid foundation under the beam. When the following values are used:

$$
\begin{aligned}
& E=81 \times 10^{6} \text { psi, } I=1 / 12 \text { in. }^{4}, \\
& L=9 \text { in. }, \delta=0.009 \text { in., } \\
& p L=400 \text { lbs., }
\end{aligned}
$$

the maximum vertical displacement given by Eq. (2) is equal to the gap width $\delta$, so that node 14 should contact the foundation, e.g., node 25 . However, the vertical displacement of node 14 as given by the finite element solution is only $59 \%$ of this value due to the inability of the compatible linear displacement field to represent the pure bending mode (Ref. 13, Section 9.3). In fact, even with model $\mathrm{B}$, the center span displacement is determined to only $87 \%$ of the exact value. Since our primary interest is in the behavior of the gap closure algorithm, we arbitrarily increase the distributed load to three times the magnitude which gives the exact center span displacement value of 0.009 inches. Model B is used with horizontal symmetry specified at $R=0$ (that is $U_{R}=0$ at node 86 ), a 
THE JOHNS MOPKINS UNIVERSITY

APPLIED PHYSICS LABORATORY

LAUPEL MAFYLAND

simple support condition at node $104\left(U_{Z}=0\right)$, and zero displacement specified for nodes 106-124. Since nodes 106-124 are fixed, contact will occur when one or more gap elements (81-98) undergoes full closure.

Three variations on this problem will be considered, all with the input values given above. The first case, which involves only elastic behavior, is summarized in Table IIIa and Fig. 4a. For the first iteration a uniform gap modulus of 1 psi was used and resulted in a maximum gap closure of $260 \%$ (Fig. 4a) with 14 of 18 gap elements indicating closure. Notice in the Table, that the converged solution for the bending stress, $\sigma_{R}$, in the center span element 62 is about $1 / 3$ the initial value. The peak bending stress is 7700 psi and occurs in a location near the point of separation of the beam from the wa11.

For Case 2, we perform an elastic-plastic analysis of this problem with a bilinear stress-strain curve. The yield stress was set at 10,000 psi and the secondary slope of the bilinear curve was E/3. However we know from Case 1, all stresses in the converged solution should be less than 8000 psi. Therefore, although some elements will yield during the iteration process, the final result for Case 2 should be a duplicate of Case 1 with no structural elements above the yield stress. Examination of Table IIIb and Fig. 4b shows this indeed to be so. The slight difference in tabulated stress (7160 versus $6913 \mathrm{psi}$ ) is a result of the $\pm 5 \%$ closure tolerance. Case 2 shows that elasticplastic effects tended to speed convergence in this problem. 
Table IIIa

Gap Closure Test Problem: 3

Beam Bending with

Uniform Load - Case 1

Elastic Solution

\begin{tabular}{|c|c|c|c|c|}
\hline $\begin{array}{c}\text { Iteration } \\
\text { No. }\end{array}$ & $\begin{array}{c}\text { Avg. } \\
\text { Gap } \\
\text { Closure } \\
(\%)\end{array}$ & $\begin{array}{c}\text { Bending } \\
\text { Stress } \\
\sigma_{\mathrm{R}}{ }^{\mathrm{F}} \\
(\mathrm{psi})\end{array}$ & $\begin{array}{c}\text { Number } \\
\text { of Closed } \\
\text { Gap } \\
\text { Elements }\end{array}$ & $\begin{array}{c}\text { Number } \\
\text { of Non- } \\
\text { Converged } \\
\text { Gap } \\
\text { Elements }\end{array}$ \\
\hline 1 & 201.4 & 20937 & 14 & - \\
2 & 197.7 & 20521 & 14 & 13 \\
3 & 196.7 & 19599 & 13 & 13 \\
4 & 180.2 & 17793 & 13 & 15 \\
5 & 160.2 & 14984 & 12 & 15 \\
6 & 139.1 & 11879 & 10 & 14 \\
7 & 118.9 & 9502 & 9 & 14 \\
8 & 109.6 & 8127 & 7 & 13 \\
9 & 105.6 & 7436 & 5 & 13 \\
10 & 103.5 & 7096 & 4 & 1 \\
11 & 102.0 & 6913 & 4 & 0 \\
\hline
\end{tabular}

${ }^{\dagger}$ Gap Elements No. 81-98 in Model B

${ }^{\ddagger}$ Element No. 62 

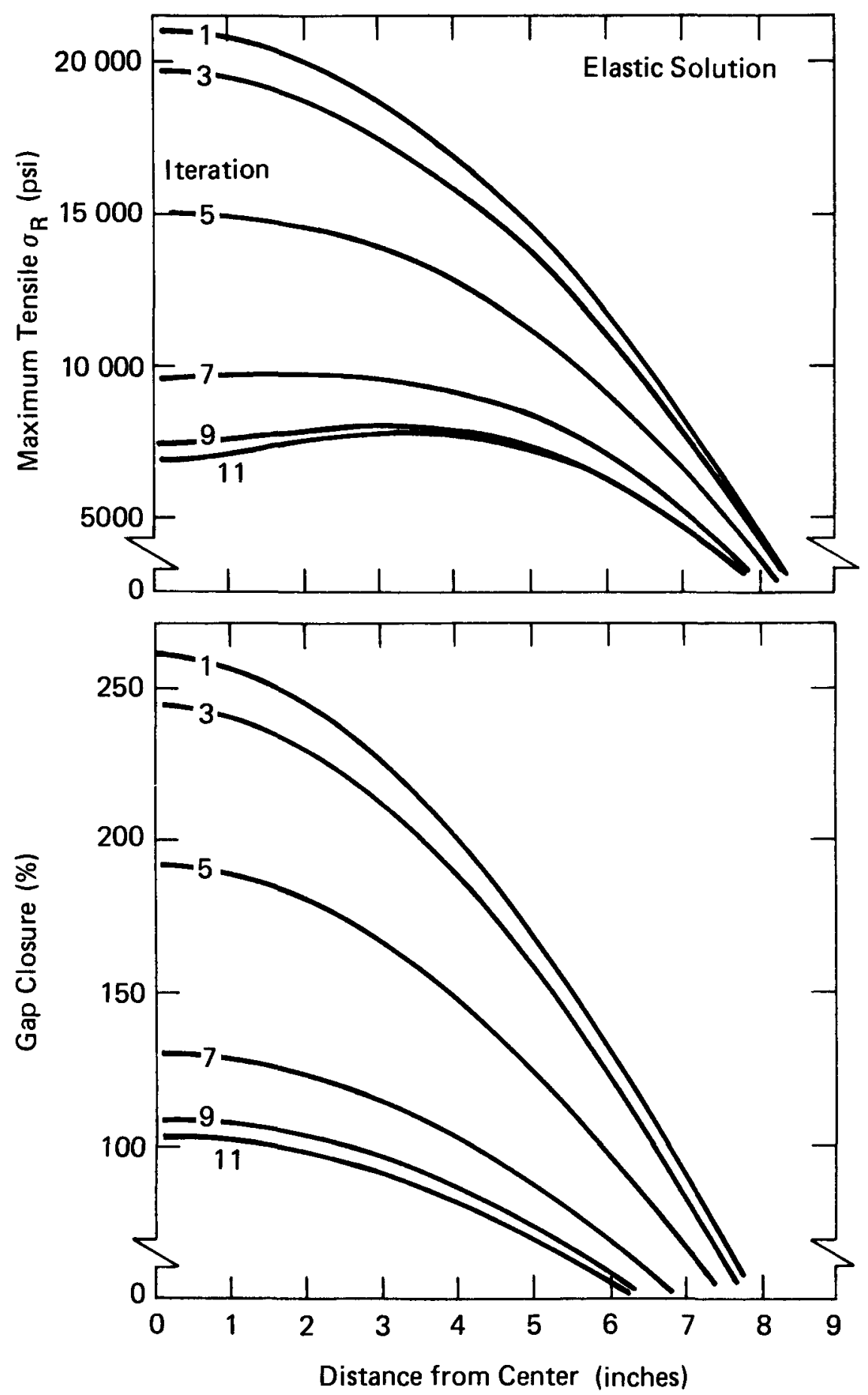

Fig. 4a Beam Bending with Uniform Load - Case 1 
Table IIIb

Gap Closure Test Problem: 3

Beam Bending with

Uniform Load - Case 2

Elastic Solution*

\begin{tabular}{|c|c|c|c|c|}
\hline $\begin{array}{c}\text { Iteration } \\
\text { No. }\end{array}$ & $\begin{array}{c}\text { Avg. } \\
\text { Gap } \\
\text { Closure } \\
(\%)\end{array}$ & $\begin{array}{c}\text { Bending } \\
\text { Stress } \\
\sigma_{\mathrm{R}}^{\text {F }} \\
(\mathrm{ps})\end{array}$ & $\begin{array}{c}\text { Number } \\
\text { of Closed } \\
\text { Gap } \\
\text { Elements }\end{array}$ & $\begin{array}{c}\text { Number } \\
\text { of Non- } \\
\text { Converged } \\
\text { Gap } \\
\text { Elements }\end{array}$ \\
\hline 1 & 201.4 & 20937 & 14 & - \\
2 & 247.1 & 18635 & 15 & 16 \\
3 & 256.3 & 16211 & 14 & 14 \\
4 & 201.4 & 12419 & 14 & 16 \\
5 & 147.5 & 8680 & 11 & 15 \\
6 & 114.9 & 7366 & 7 & 13 \\
$8 * *$ & 103.4 & 7349 & 5 & 13 \\
\hline 8 & 103.6 & 7160 & 4 & 0 \\
\hline
\end{tabular}

${ }^{\dagger}$ Gap Elements No. 81-98 in Model B

${ }^{\ddagger}$ Element No. 62

*Yield Stress $=10000$ psi

Secondary Slope $=1 / 3$ Young's Modulus

**Elastic-Plastic Convergence 

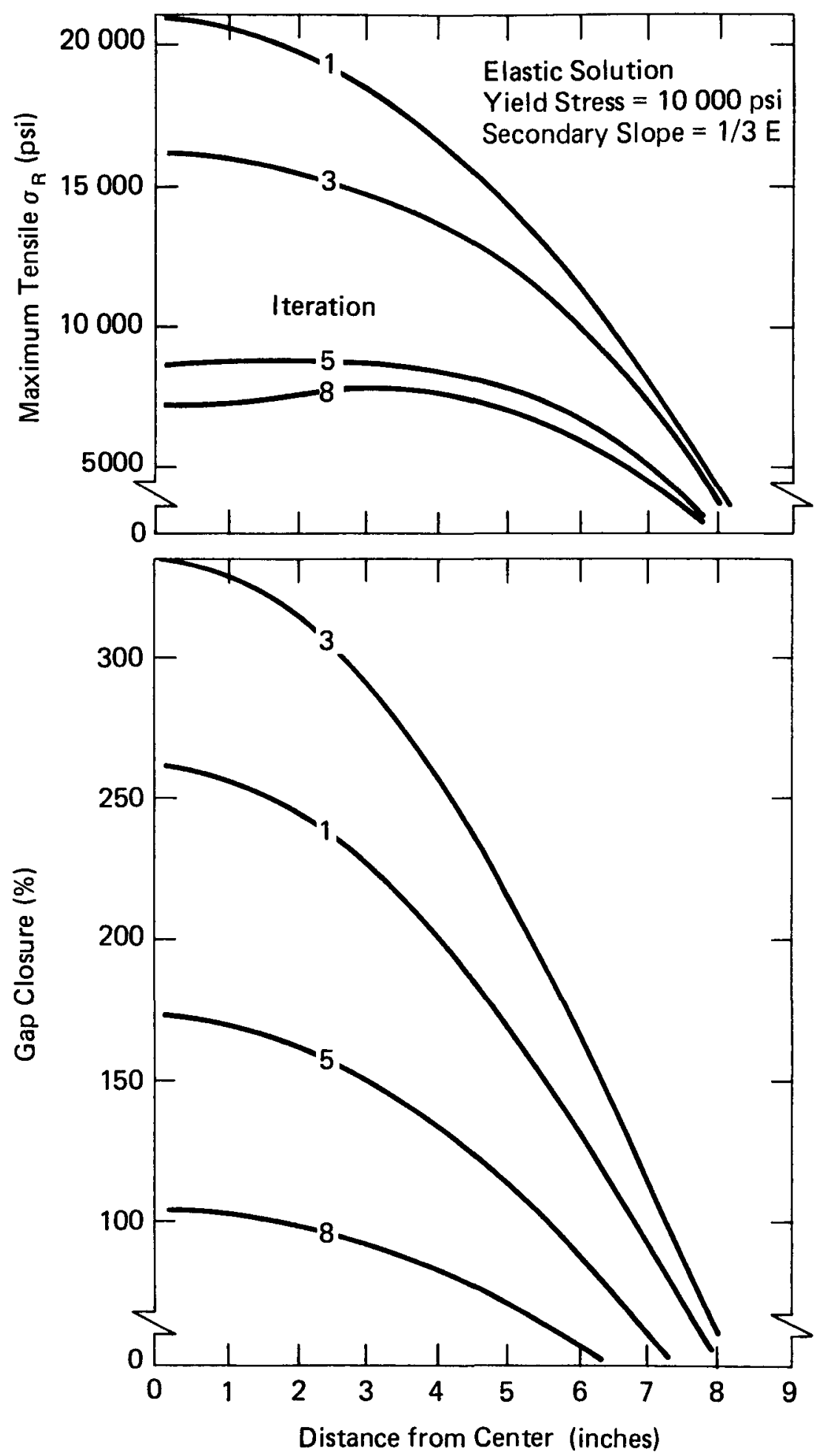

Fig. 4b Beam Bending with Uniform Load - Case 2 
As a final variation, a yield stress of 7000 psi is used to provide a problem in which some elements are above yield in the converged solution. The numerical behavior is summarized in Table IIIc and Fig. 4c. The Table shows that gap convergence occurs after 8 iterations. However, the program keeps iterating to obtain a converged elastic-plastic solution. After 13 iterations only 1 element, element 65, has failed to converge in an elasticplastic sense. However, the change in stress from the previous iteration is less than $20 \mathrm{psi}$. As in the previous cases the peak stress (7367 psi) occurs in the ragion of greatest curvature where the beam separates from the wall.

These three sample problems illustrate the general behavior of the gap closure algorithm. They also serve as an introduction to the two MHW heat shield problems discussed in the next section. 
Table IIIc

Gap Closure Test Problem: 3

Beam Bending with

Uniform Load - Case 3

Elastic-Plastic Solution*

\begin{tabular}{|c|c|c|c|c|}
\hline $\begin{array}{c}\text { Iteration } \\
\text { No. }\end{array}$ & $\begin{array}{c}\text { Avg. } \\
\text { Gap } \\
\text { Closure } \\
(\%)\end{array}$ & $\begin{array}{c}\text { Bending } \\
\text { Stress } \\
\sigma_{R}{ }^{\neq} \\
(p s i)\end{array}$ & $\begin{array}{c}\text { Number } \\
\text { of Closed } \\
\text { Gap } \\
\text { Elements }\end{array}$ & $\begin{array}{c}\text { Number } \\
\text { of Non- } \\
\text { Converged } \\
\text { Gap } \\
\text { Elements }\end{array}$ \\
\hline 1 & 201.4 & 20937 & 14 & - \\
2 & 278.9 & 17791 & 15 & 16 \\
3 & 283.3 & 15871 & 15 & 15 \\
4 & 206.8 & 10595 & 14 & 16 \\
5 & 136.9 & 6321 & 10 & 14 \\
6 & 108.1 & 5713 & 6 & 13 \\
7 & 100.9 & 6266 & 3 & 13 \\
8 & 100.4 & 6676 & 3 & 0 \\
9 & 101.5 & 6747 & 3 & 0 \\
10 & 101.3 & 6705 & 4 & 0 \\
11 & 101.2 & 6629 & 4 & 0 \\
12 & 101.7 & 6554 & 3 & 0 \\
13 & 101.4 & 6488 & 3 & 0 \\
\hline
\end{tabular}

${ }^{\dagger}$ Gap Elements No. 81-98 in Model B

${ }^{\ddagger}$ Element No. 62

*Yield Stress $=7000 \mathrm{psi}$

Secondary Slope $=1 / 3$ Young's Modulus 

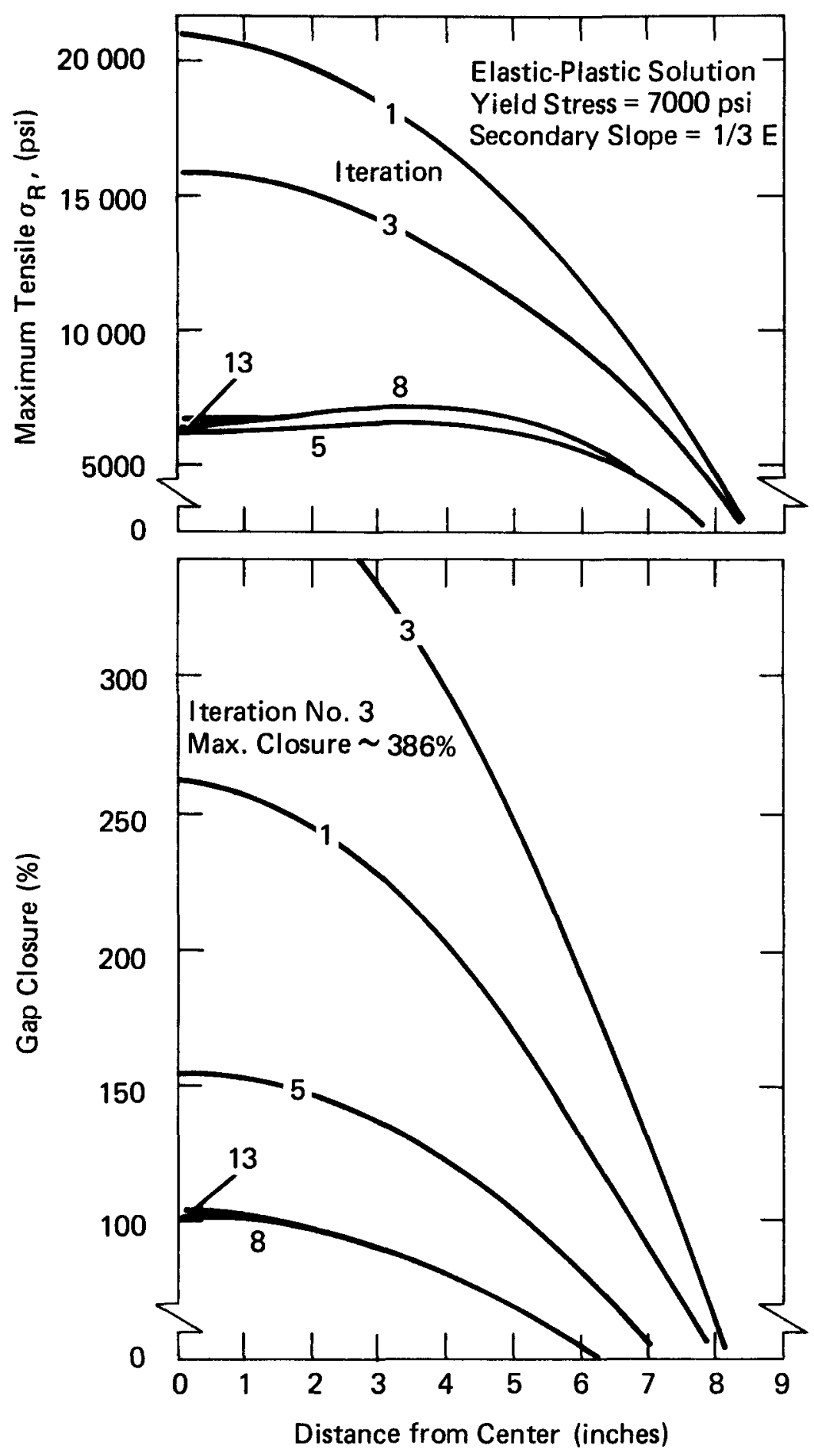

Fig. 4c Beam Bending with Uniform Load - Case 3 


\section{MHW AEROSHELL GAP CLOSURE PROBLEMS}

One of the major components of the Multi-Hundred Watt Radioisotope Thermoelectric Generator (MHW-RTG) is the nuclear fueled Heat Source Assembly. The Heat Source (Fig. 5) is about 17 inches 1ong, 7.2 inches in diameter and contains three eight-pack Fuel Sphere Assemblies (FSA) arranged in a helical pattern. The cylindrical aeroshel1 is made of isotropic graphite POCO AXF-5Q which acts as a heat shield in the event of post launch failure leading to atmosphere reentry of the spacecraft. The end-caps, which are also made of POCO graphite, screw into the ends of the heat shield wall.*

In a reentry situation, the Heat Source will stabilize in a side-on configuration or in the less probable end-on mode. Each of these reentries involves structural components which contact across gaps or separations. We consider each of these reentry attitudes in turn.

\section{Problem (1) Side-on Reentry with Therma1-Mechanica1 Loading}

In the side-on stable reentry, the heat shield can experience a severe thermal environment while decelerating in the atmosphere. The external pressure distribution is counterbalanced by the inertial loading from the fuel spheres and retainer ring assembly. The initial structural modeling simplified the load transfer process (from the retainer ring to the heat shield across a 0.045 inch gap) by applying the inertial loading directly to the inside wall of the heat shield. For a heat source released at 221,692 ft. with a velocity and entry angle of $35,030 \mathrm{fps}$ and $-46.4^{\circ}$, the peak deceleration is 230 gees. Fig. 6 shows the mechanical load system on the heat shield due to the peak deceleration. Superimposing this load system on the maximum thermal stress condition (which occurred at $5.75 \mathrm{sec}$. ) increased the maximum tensile stress in the plane from

*A subsequent design uses a snap ring concept. 


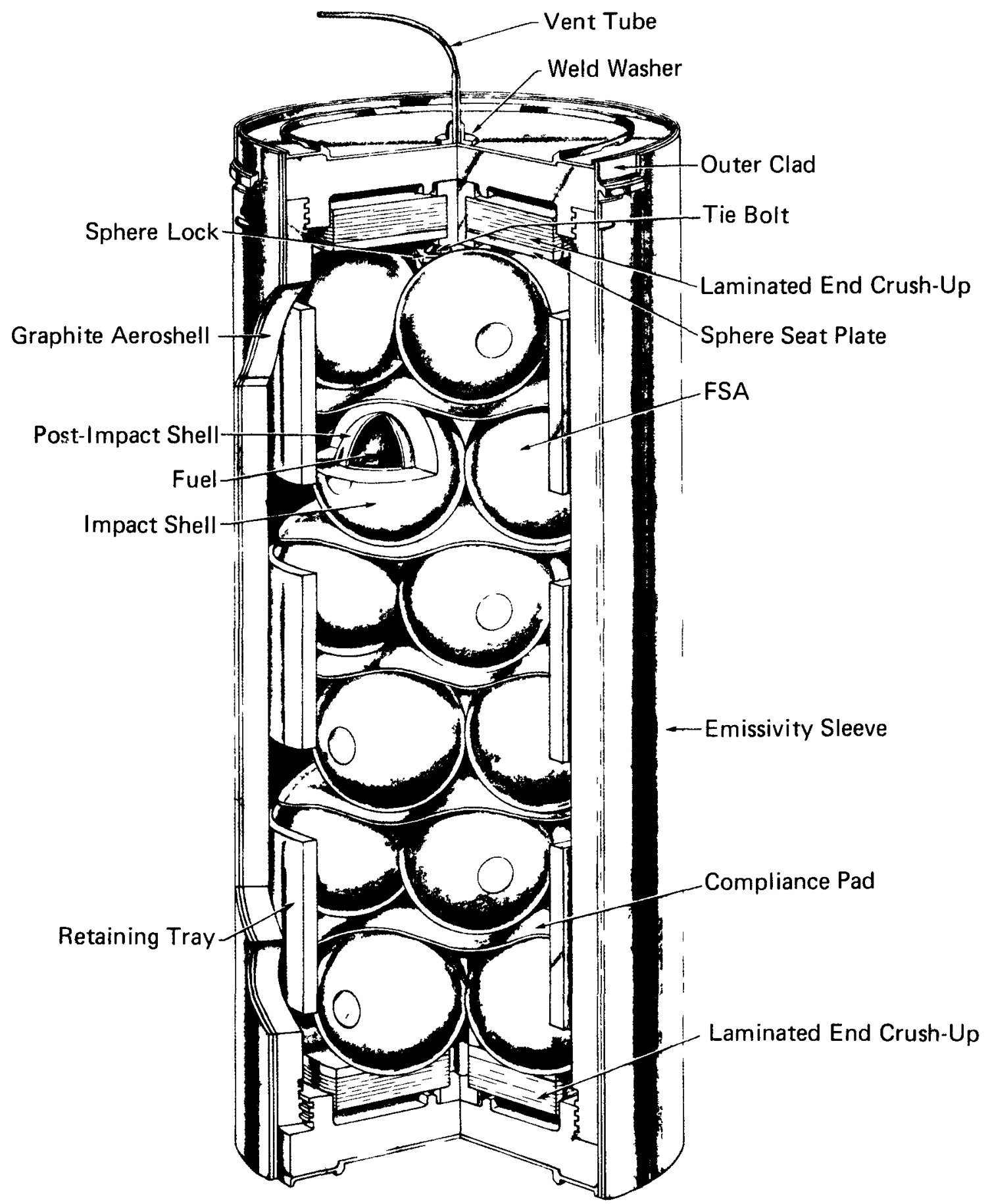

Fig. 5 The MHW Heat Source (Figure Extracted from General Electric Report) 


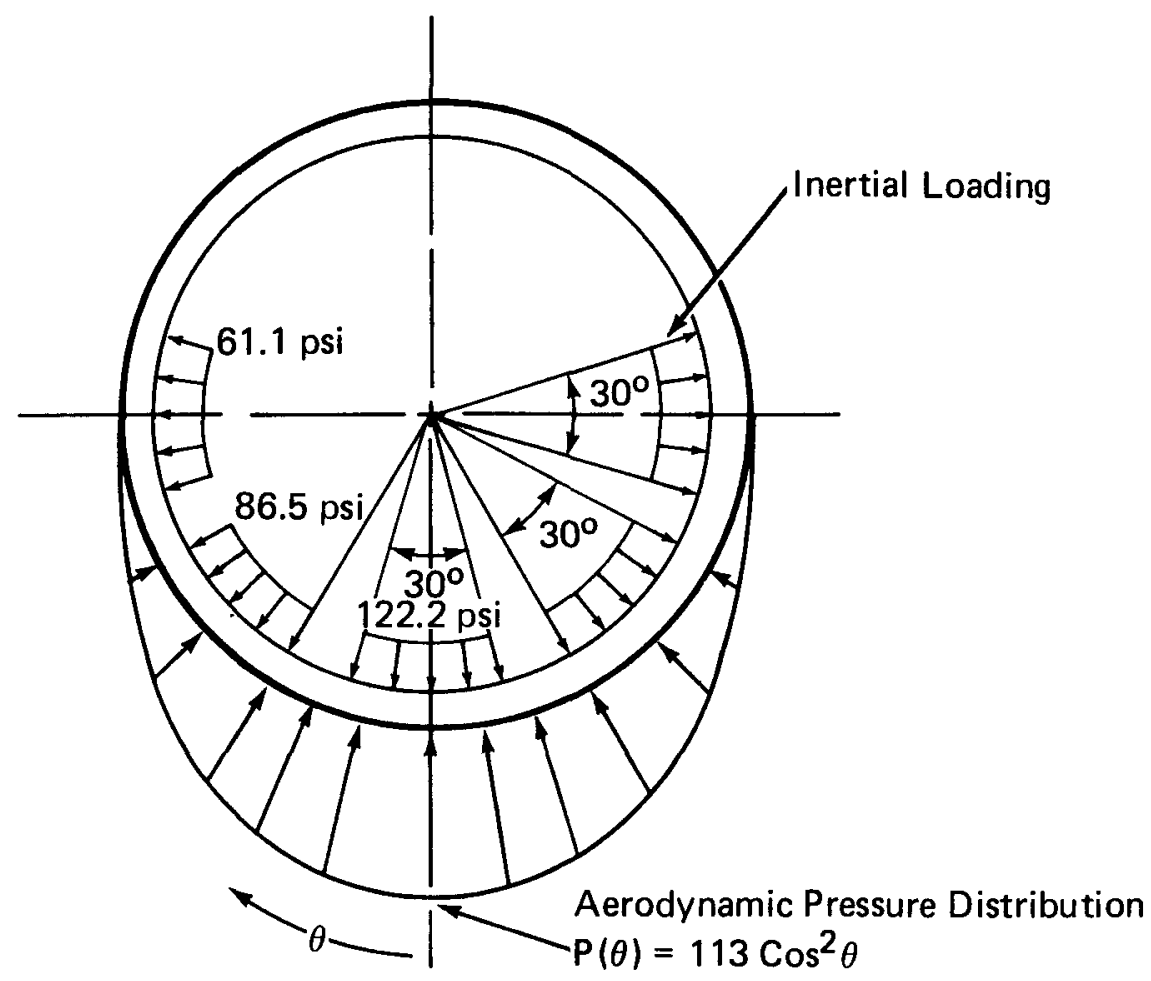

Fig. 6 Heat Shield Load Distribution, Side-On Reentry 
$1800 \mathrm{psi}$, for thermal load only, to $5250 \mathrm{psi}$. These plane stress tensile values, which are essentially hoop stress, occur on the inside wall near the stagnation line (actually $2.5^{\circ}$ off stagnation). Since, in this case, the mechanical loading causes the major portion of the critical stress, an improved model was devised to account for the inertial load transfer across the gap between the retainer ring and heat shield. In this model, the inertia loading of the FSA's is applied to the inside wall of the retainer ring rather than to the heat shield.

The finite element model used in the subsequent gap closure analysis is shown in Figs. 7 and 8. The model has 504 elements (36 gap elements) and 555 nodes. Fig. 8 is an expanded wall representation, and is useful for presenting contour plots (Ref. 14) of temperature, stress and strain. For example, a contour plot for the temperature distribution is shown in Fig. 9 with the Pyrocarb retainer ring maintained at $2000^{\circ} \mathrm{F}$. On this plot, the superscript notation indicates the power of ten by which the number is to be multiplied.

We first give the significant results of the retainer ring/heat shield gap closure analysis, and then discuss specific numerical characteristics of the problem. The peak tensile stress in the heat shield again occurs on the inside wall with a value of $4540 \mathrm{psi}\left(2.5^{\circ}\right.$ away from stagnation). This compares to 5250 psi obtained with the original model. A contour plot of maximum principal stress in the plane is shown in Fig. 10 for the undeformed mode1. The maximum tensile stress in the retainer ring occurs at $90^{\circ}$ and is typically 3200 psi. Fig. 11 illustrates the nature of the gap closure. In this figure, hoop stress contours are superimposed on the deformed (expanded wa11) mode1. The gap has closed over a $70^{\circ}$ sector from the stagnation point while at $180^{\circ}$, a separation of over $400 \%$ has developed. 
THE JOHNS HOPKINS UNIVERSITY

APPLIED PHYSICS LABORATORY

LAUREL. MARYLAND

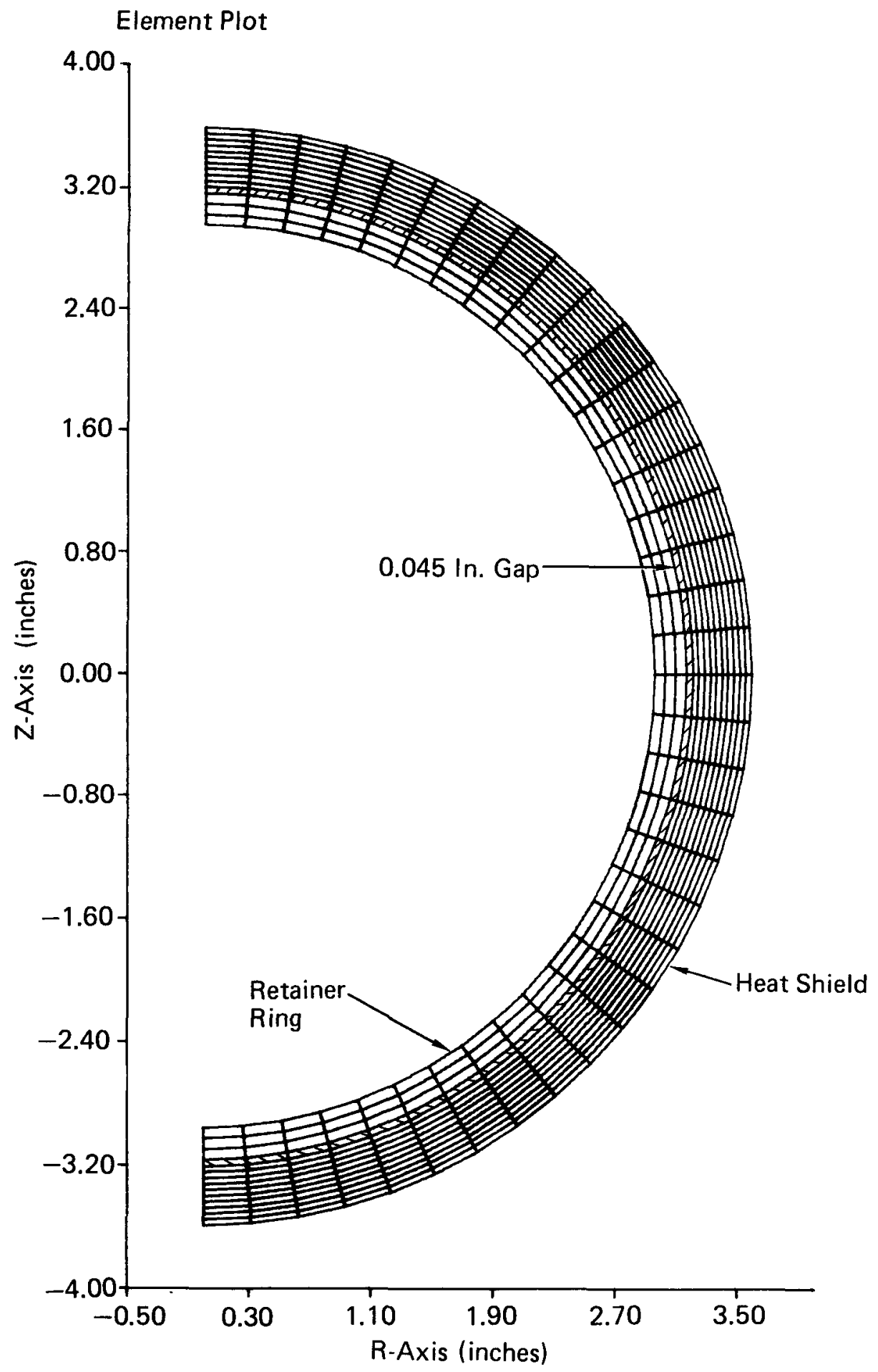

Fig. 7 Finite Element Model for Side-On Stable Reentry Analysis 
Element Plot

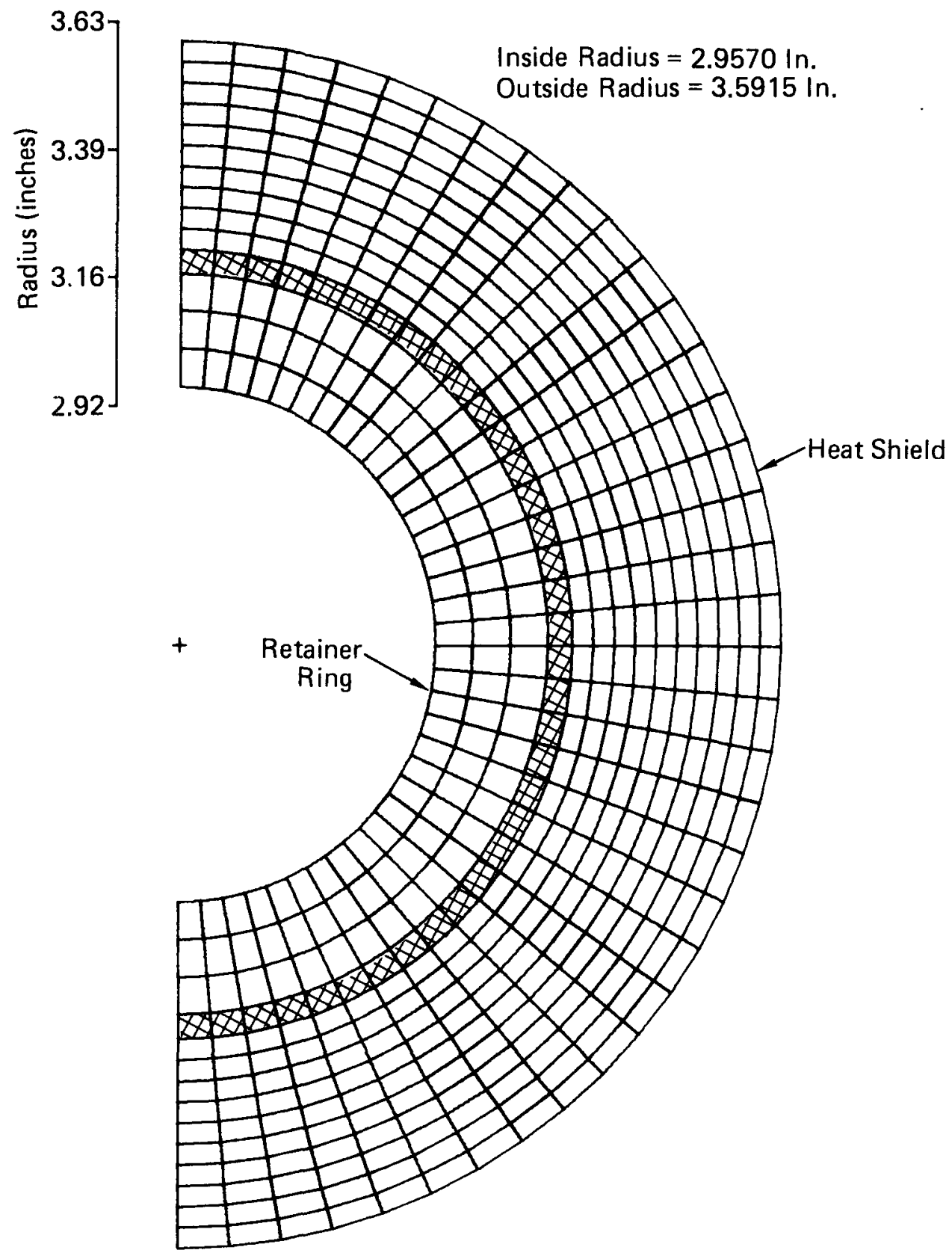

Fig. 8 Expanded Wall Representation of Finite Element Model 


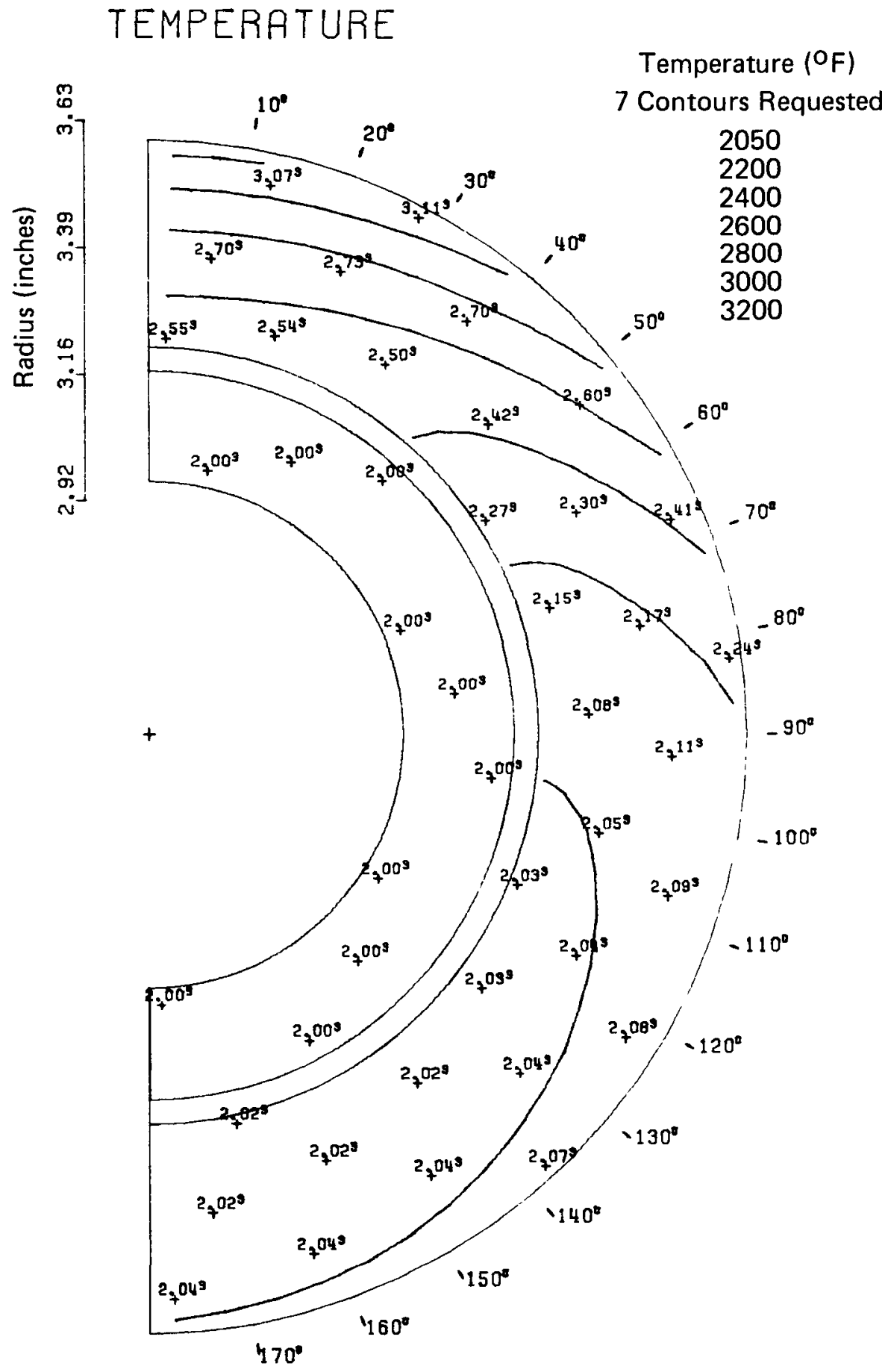

Fig. 9 Temperature Contours for Side-On Reentry Analysis 


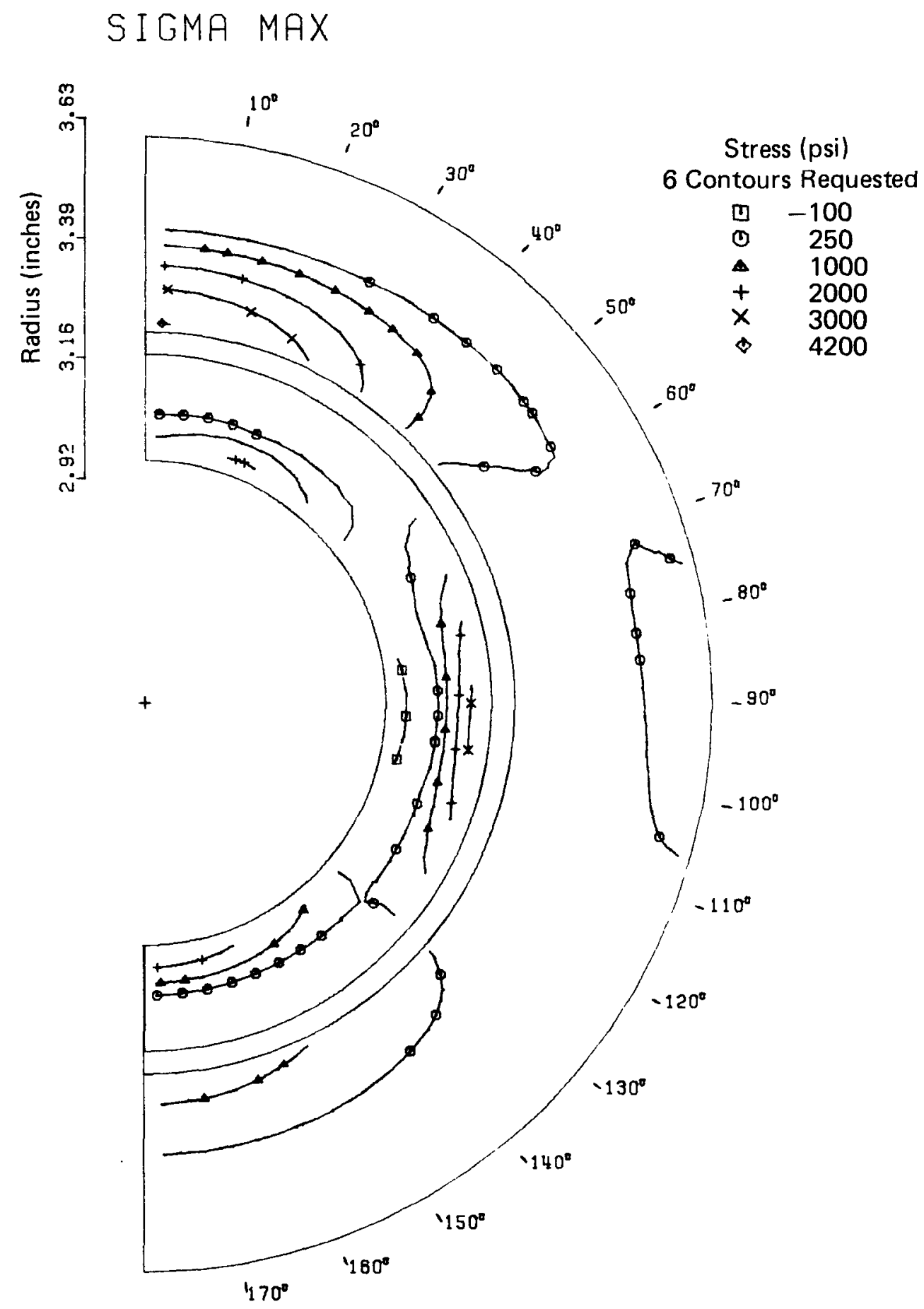

Fig. 10 Contours of Maximum Stress in the Plane for Side-On Reentry 


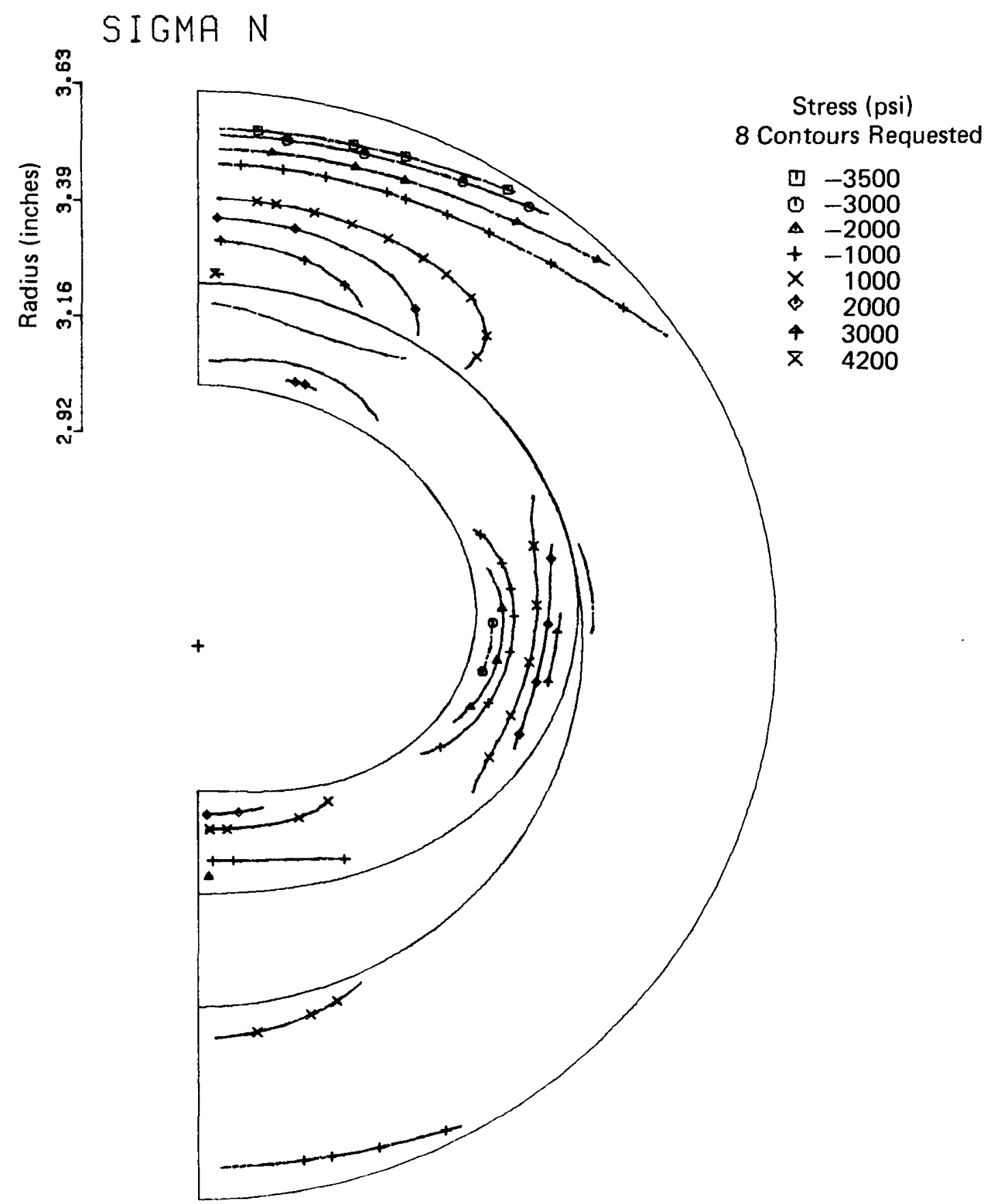

Fig. 11 Contours of Hoop Stress for Side-On Reentry 
The process of closing gaps leading to eventual contact between the heat shield and retainer ring is particularly interesting in this problem. In fact, this problem provided the focal point for developing the gap closure algorithm. The various numerical schemes tried, as well as the results obtained during the development process, will not be discussed here due to length limitations. * We shall discuss but one set of numerical results those obtained with the current gap closure algorithm.

Before proceeding we hasten to emphasize that the retainer ring must displace vertically as a rigid body before contacting the heat shield. To confine the rigid body movement to reasonable limits during the iteration process a reduction in tensile gap modulus of 20-5-1-1-1 (etc.) psi was employed. The numerical behavior during this schedule is sumarized in Table IV and in Figs. 12 and 13. With a uniform modulus of $20 \mathrm{psi}$ in the gap elements, a maximum element tensile hoop stress of $4465 \mathrm{psi}$ is computed. The initial solution is "suitable" since the maximum compressive gap strain is less than $-100 \%$. ** Convergence is complete after six iterations with nine gaps closed (i.e. contact to about $72^{\circ}$ as shown in Fig. 12, curve 6). Notice in Fig. 13 that gap closure for the converged solution, curve 6 , has responded to the $30^{\circ}$-sector type inertial loading (refer to Fig. 6).

\footnotetext{
"Two of the early schemes included (i) using a stiffening factor to increase the modulus of compression gaps while the tension gaps were relaxing, and (ii) adding a corrective modulus to the compressive gap modulus based on the local gap strain in relation to the average strain of overclosed gaps: a socalled "shape correction".

** Initial gap moduli of 50 and 75 psi were not suitable since they gave maximum closures of on $1 \mathrm{y} 55 \%$ and $24 \%$, respectively.
} 
Table IV

Retainer Ring/Gap/Aeroshell Problem*

\begin{tabular}{|c|c|c|c|c|}
\hline $\begin{array}{c}\text { Iteration } \\
\text { No. }\end{array}$ & $\begin{array}{c}\text { Avg. } \\
\text { Gap } \\
\text { Closure } \\
(\%)\end{array}$ & $\begin{array}{c}\text { Number } \\
\text { of Closed } \\
\text { Gaps }\end{array}$ & $\begin{array}{c}\text { Number } \\
\text { of Non- } \\
\text { Converged } \\
\text { Gaps }\end{array}$ & $\begin{array}{c}\text { Max. } \\
\sigma_{\theta} \\
(\mathrm{psi})\end{array}$ \\
\hline 1 & 151.7 & 8 & - & 4465 \\
2 & 125.5 & 15 & 18 & 3848 \\
3 & 126.7 & 18 & 20 & 3974 \\
4 & 108.3 & 8 & 19 & 4173 \\
5 & 102.1 & 10 & 10 & 4223 \\
6 & 101.4 & 9 & 0 & 4223 \\
\hline
\end{tabular}

†For Elements with

Gap Strain <-100\%

*Problem Specifications: Programmed Nonisotropic Gaps

Tensile Gap $E_{M}=$ 20-5-1-etc.

$$
E_{N}=E_{T}=\left(E_{M} \text { for Tensile Gap }\right)
$$




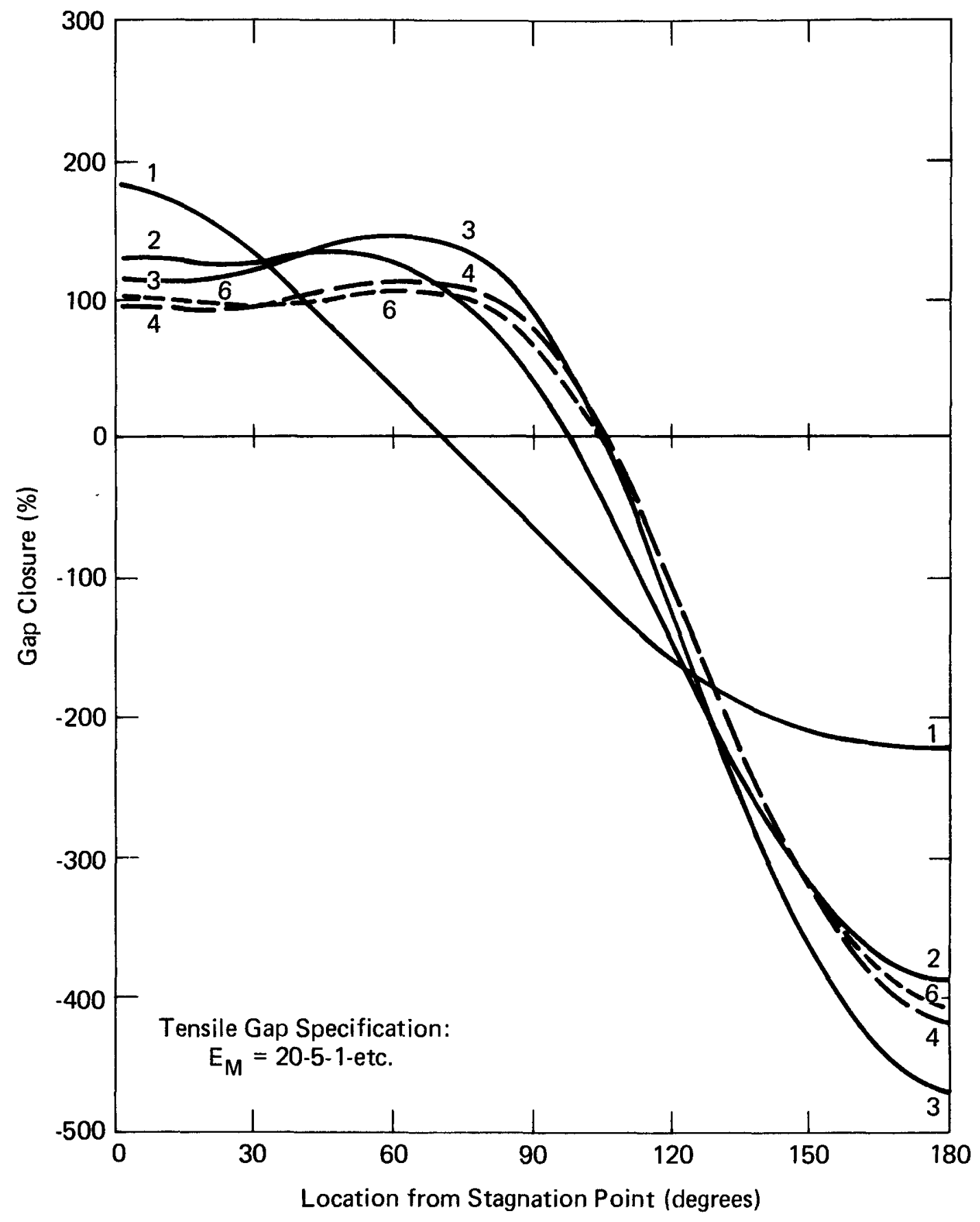

Fig. 12 Retainer Ring/Gap/Aeroshell Problem - All Gap Elements 


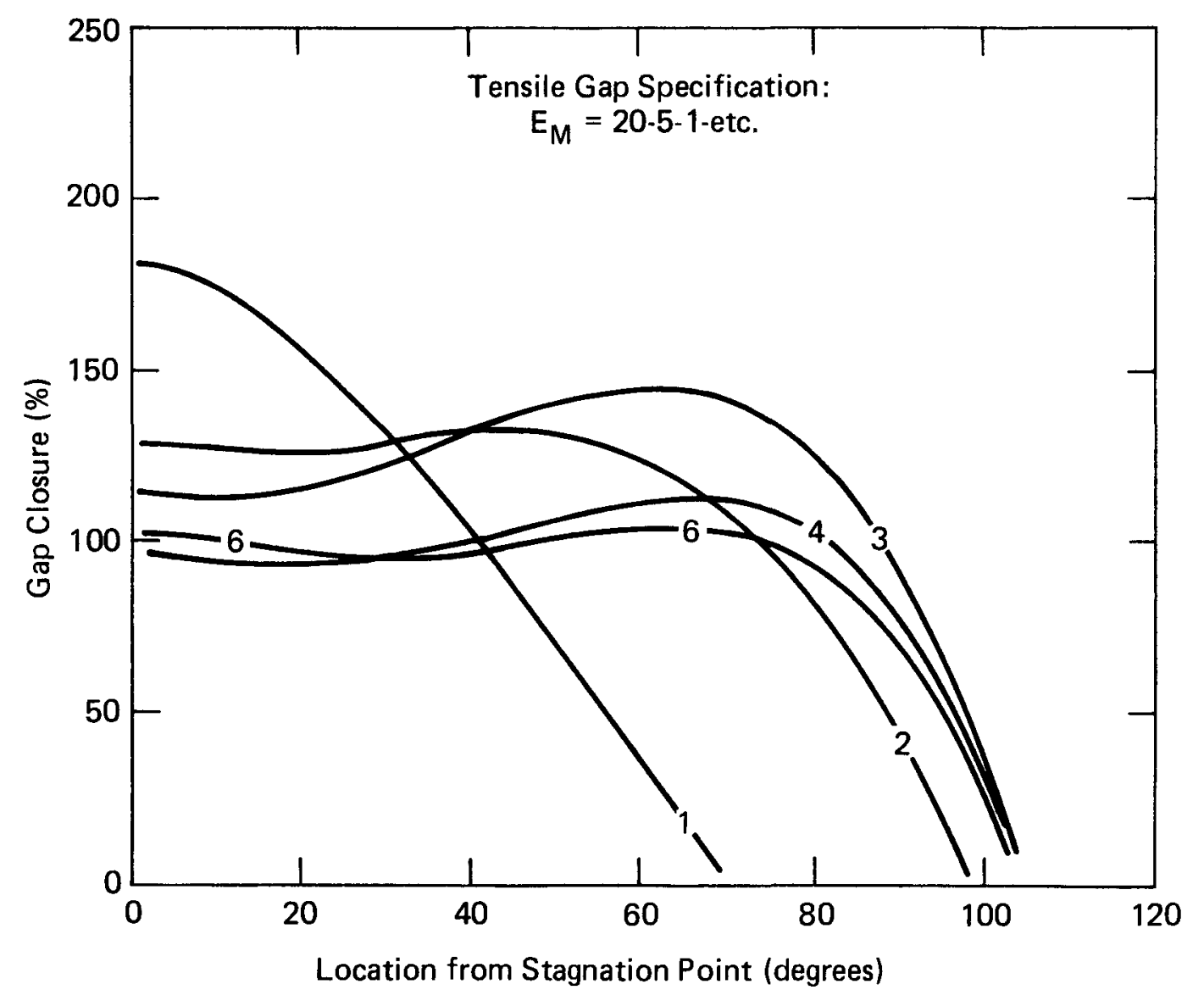

Fig. 13 Retainer Ring/Gap/Aeroshell Problem - Closed Gap Elements 


\section{Problem (2) End-on Reentry with Thermal Loading}

The presence of threads as the means for joining the end caps to the barrel wall of the heat shield raises several questions on the adequacy of analysis techniques for the threaded region. The load transfer and redistribution on the thread helix due to a time varying asymetric loading is an intractable problem. The localized effects of stress concentrations at the thread roots undoubtedly dictate the limits of the design. However, we choose not to belabor these points here. Rather we describe the use of an idealized coarse model of the heat shield end region to illustrate the "essence" of the thread contact problem.

During an end-on reentry, the thermal loading is symmetric about the heat shield axis. If a series of circumferential ridges are substituted for the thread helix, then the heat shield geometry is also symmetric about its axis. Fig. 14 shows the finite element model used to study this contact problem. The model has 326 nodal points. The Z-axis is a line of rotational symmetry. Previous modeling assumed a mode of thread contact prior to analysis by specifying common nodes on the end cap and barrel threads. However, by including thin gap elements in the model between the end cap and barrel, each part is free to respond to the loading separately until contact occurs. Fig. 15 gives a detail of the thread region showing 0.010 inch gap elements $*$ as part of the mode1. As an illustration of the gap closure process, we analyze the heat shield under thermal loading only at 7.75 seconds into an end-on reentry originating at $400 \mathrm{kft}$. with $V=33,500 \mathrm{fps}$ and $Y=-83^{\circ}$. The significant results will be given first; the behavior of the gap closure algorithm wil1 be discussed next.

* Subsequent analyses have used 0.002 inch gaps. These analyses will not be discussed here. 
PHE SOHS HOFNMS UNUEESIT
APPLIED PHYSICS LABORATORY

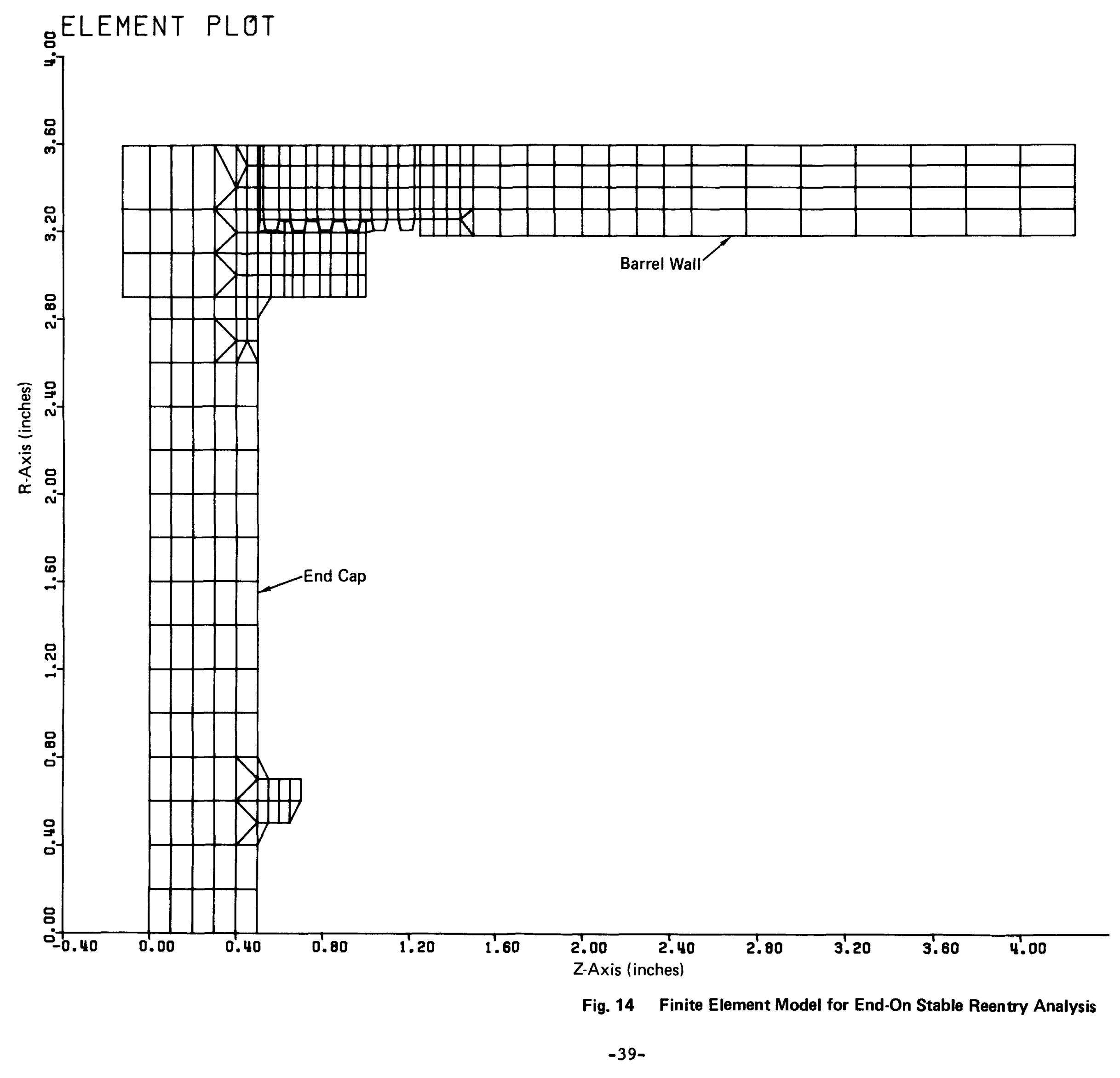




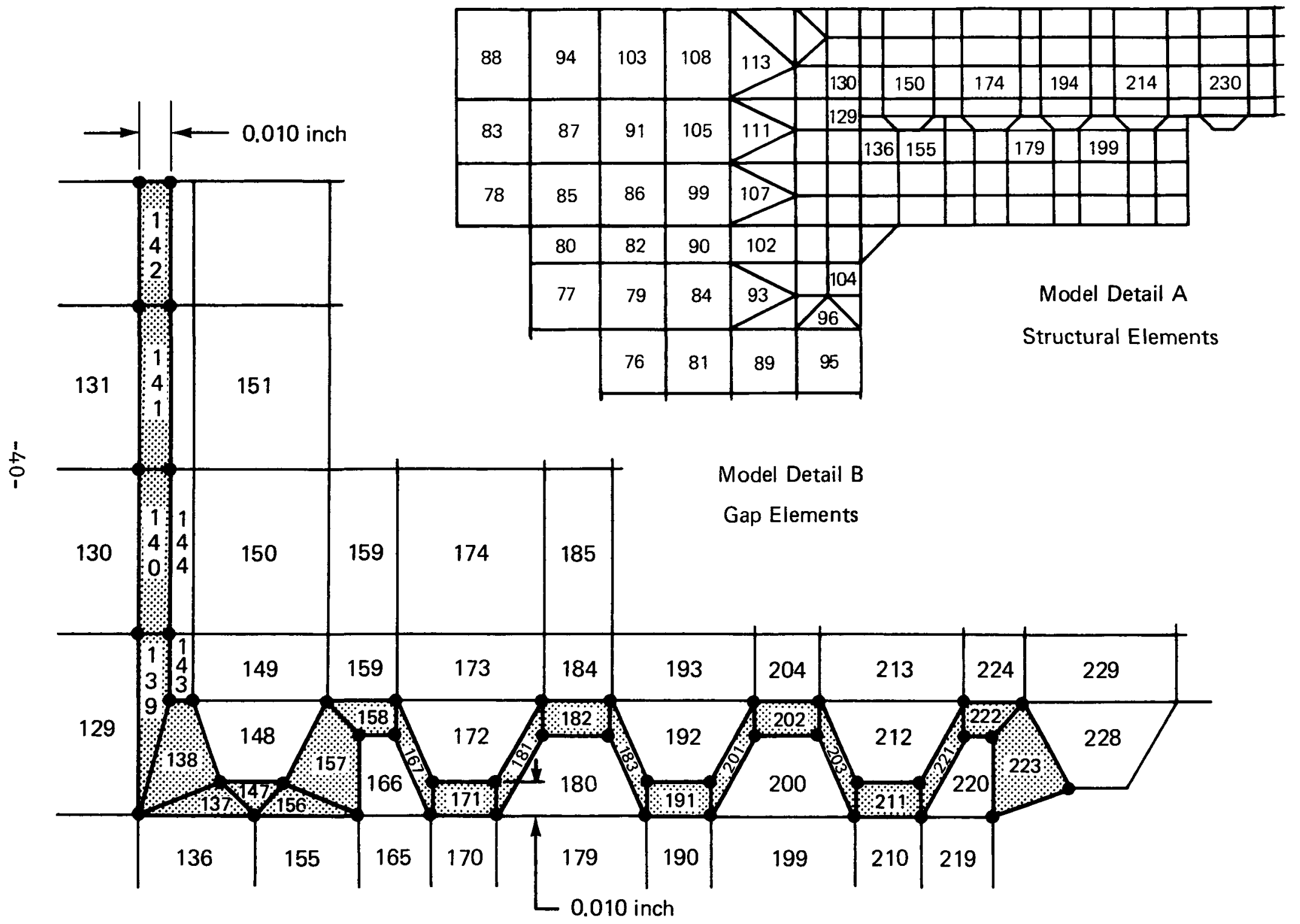

Fig. 15 End Cap/Aeroshell Barrel Gap Elements 
A contour plot giving the temperatures superimposed on the deformed mode1 is shown in Fig. 16. Contact has occurred at the outer radius on the end-face of the barrel wall and on the front face of the first full thread of the end cap. A plot of the maximum stress in the plane is shown in Fig. 17. The largest stresses occur in the "fillet elements" of the barrel wall threads and are primarily axial in nature. In the fillet above the point of thread contact the maximum principal stress is 6271 psi. The greatest value of the hoop stress is $6736 \mathrm{psi}$ and occurs midway in the end cap at $R=3.20$ inches (see Fig. 18).

Contact between the end cap and barrel wall is dependent on the thermal distribution as well as the initial gap separation. Unrestrained axial displacement of the end cap is controlled through the tensile gap modulus schedule which in this case was specified to be 100-20-5-1-1-1 (etc.) psi. The numerical behavior of this problem is summarized by Table V. For each iteration, the Table gives the number of closed gap elements, the closure for the two key gap elements (142 and 181), and stresses in the elements of maximum hoop stress (91 in the end-cap) and maximum axial stress (184 in the barrel wa11). Initially, with a 100 psi modulus in the gaps, the high stress regions are confined to the end cap. After four iterations, the supporting influence of the tensile gap elements has been completely removed. At this point, the basic algorithm would be in sole control of the closure process which has now settled down to a "push-of-war" between gap elements 142 and 181 (see Fig. 15). For this reason the modulus increases supplied by the invariance principle are insufficient to lead to a reasonable convergence rate. Therefore, an extrapolating method (to be described subsequently) was adopted to alleviate this sluggish behavior. The results shown in $\mathrm{Tab} 1 \mathrm{e} \mathrm{V}$ for iteration 6 (after an appropriate extrapolation) illustrate the substantial difference compared to the previous iteration. The 


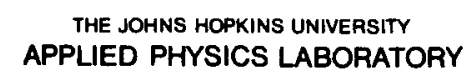

LAUREL, MarVLANO
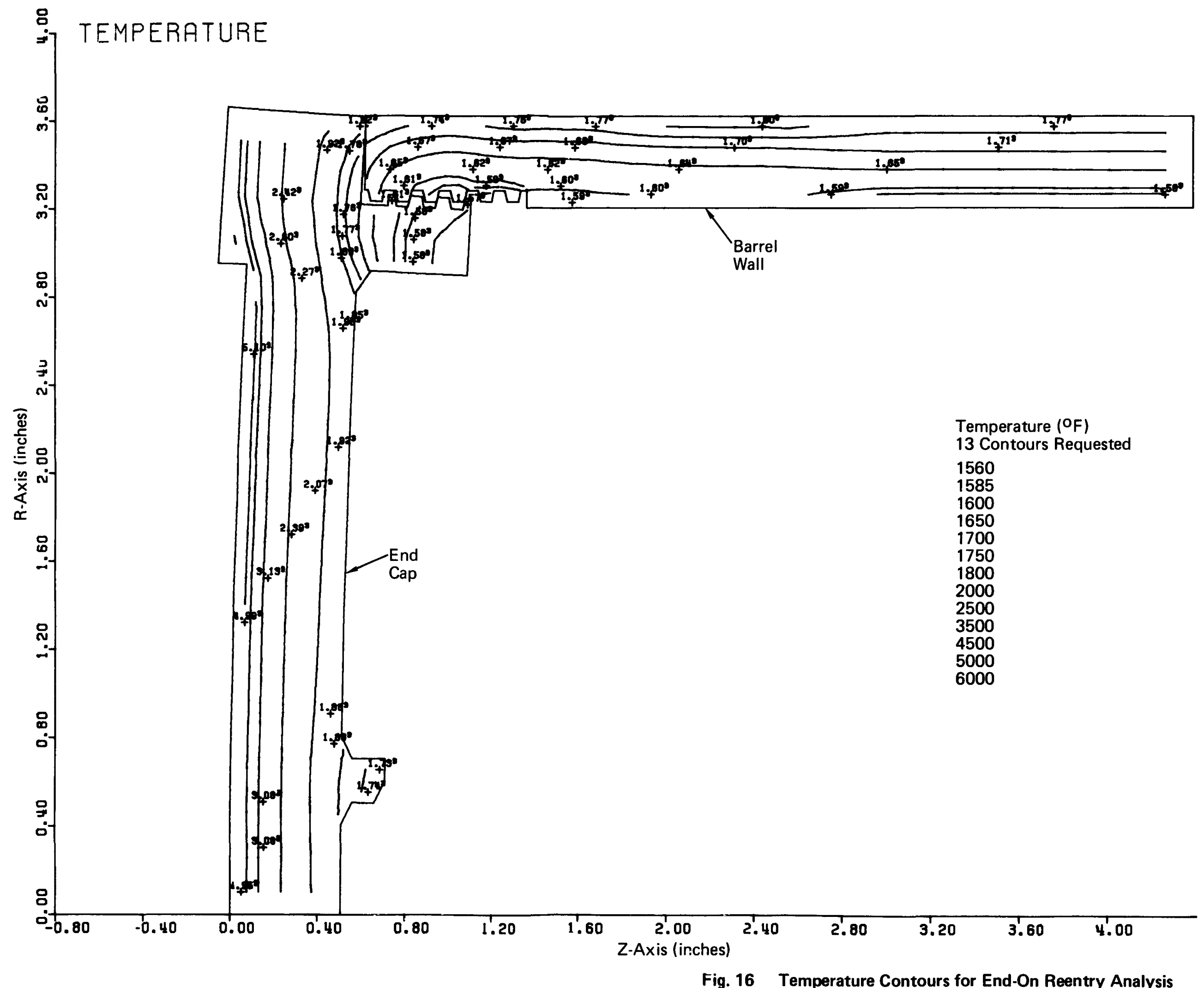
THE JOHNS HOFKINS UNIVERSTY
APPLIED PPYSICS LABORATORY

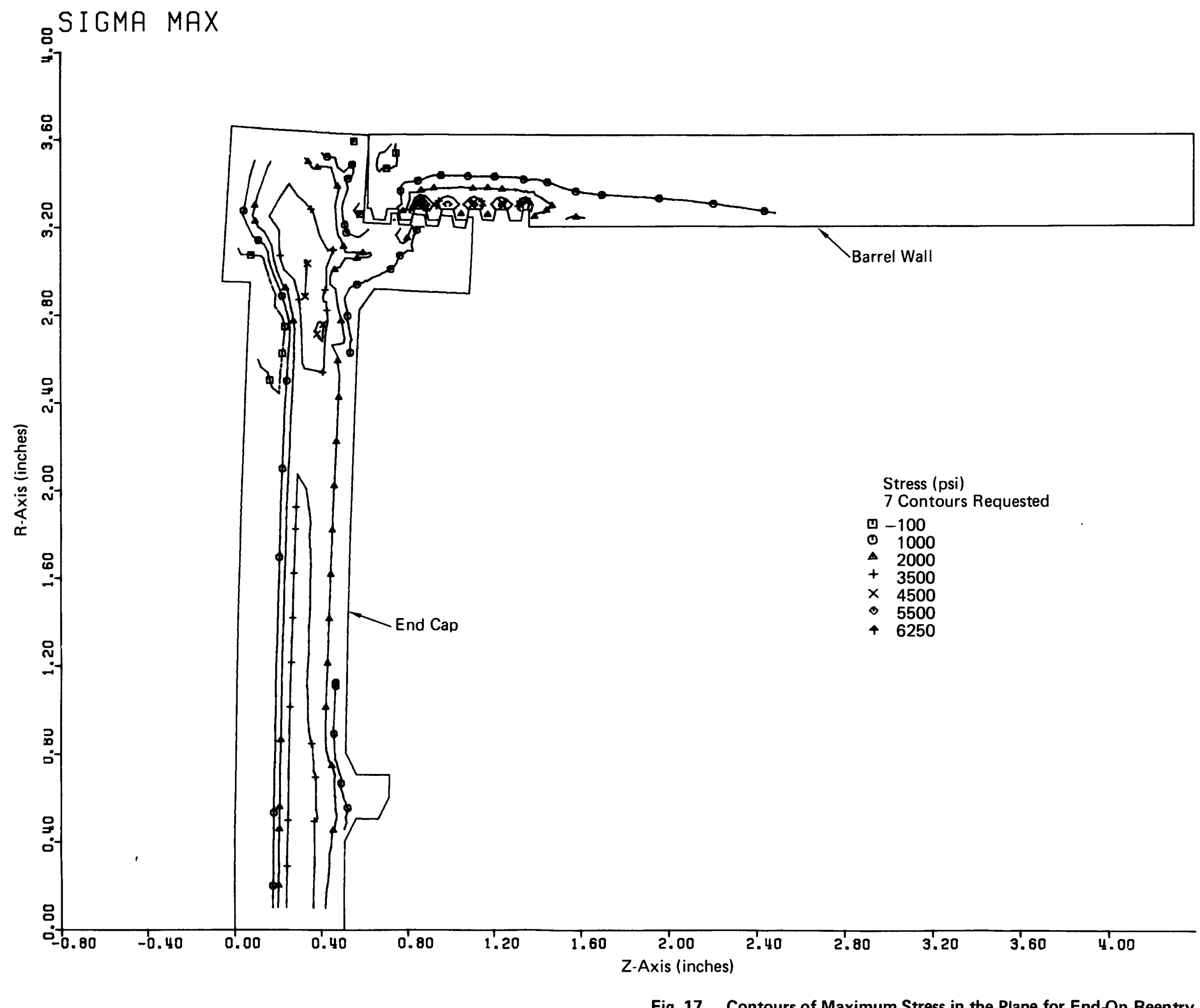


THE JOHNS HOPRINS UNIVERITY
APPLIED PHYSICS LABORATORY

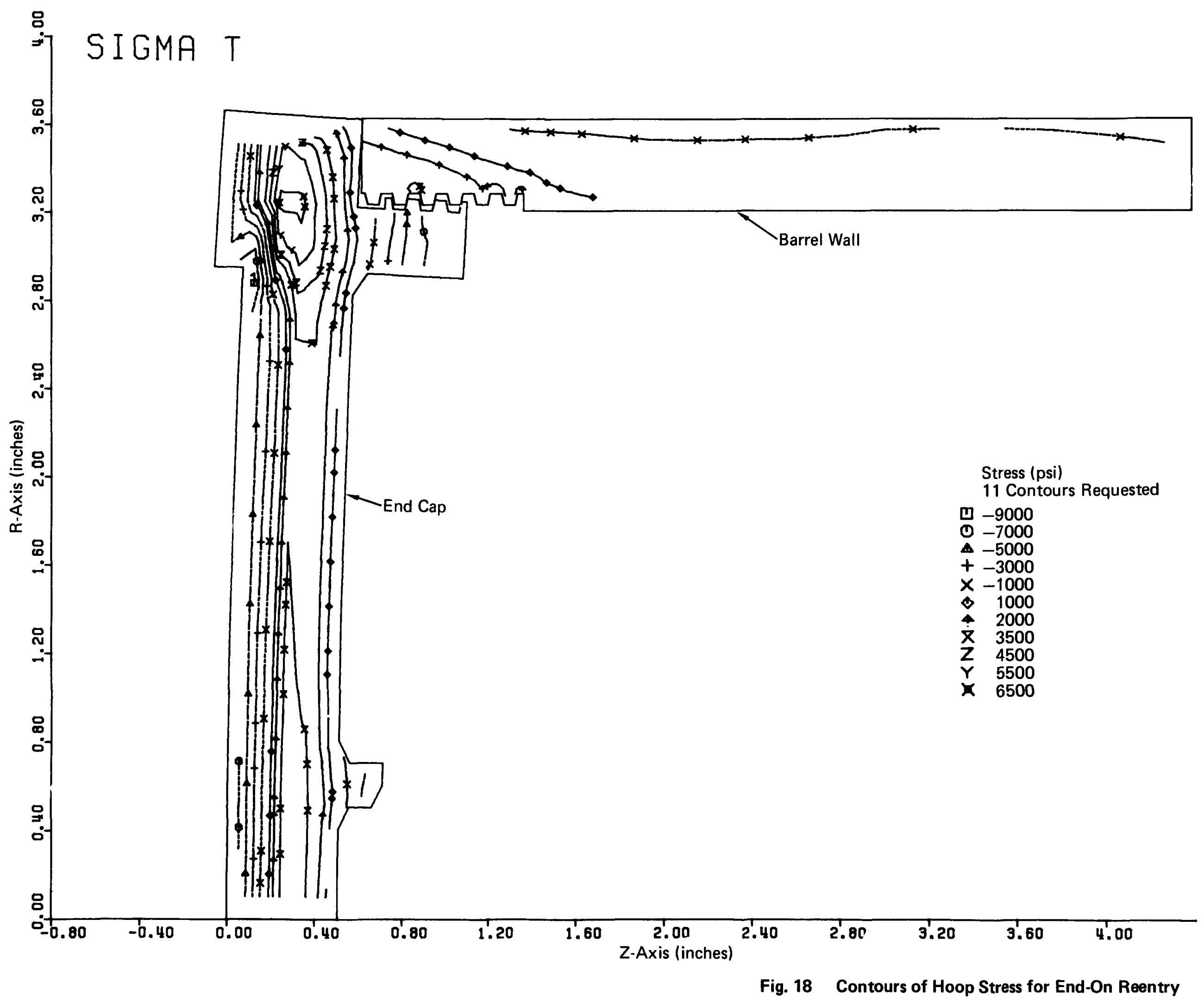


Table $\boldsymbol{Z}$

End Cap/Aeroshell Barrel Contact Problem ${ }^{\dagger}$

\begin{tabular}{|c|c|c|c|c|c|c|c|}
\hline \multirow{2}{*}{$\begin{array}{l}\text { Iteration } \\
\text { No. }\end{array}$} & \multirow{2}{*}{$\begin{array}{l}\text { Number } \\
\text { of Closed } \\
\text { Gap } \\
\text { Elements }\end{array}$} & \multicolumn{2}{|c|}{$\begin{array}{c}\text { Gap Closure } \\
(\%)\end{array}$} & \multicolumn{2}{|c|}{$\begin{array}{c}\text { Max. Hoop Stress } \\
\text { El. } 91^{*}\end{array}$} & \multicolumn{2}{|c|}{$\begin{array}{l}\text { Max. Axial Stress } \\
\text { El. } 184^{* *}\end{array}$} \\
\hline & & EI. No. 142 & El. No. 181 & $\begin{array}{c}\text { Hoop Stress } \\
\sigma_{\theta}(\mathrm{psi})\end{array}$ & $\begin{array}{c}\text { Radial Stress } \\
\sigma_{\mathrm{R}}(\mathrm{psi})\end{array}$ & $\begin{array}{c}\text { Hoop Stress } \\
\sigma_{\theta}(p s i)\end{array}$ & $\begin{array}{c}\text { Axial Stress } \\
\sigma_{z}(p s i)\end{array}$ \\
\hline 1 & 2 & 213.4 & 64.2 & 8347 & 4656 & -215 & 252 \\
\hline 2 & 4 & 134.0 & 345.9 & 7657 & 4166 & 473 & 638 \\
\hline 3 & 3 & 139.9 & 260.9 & 7531 & 4016 & 1283 & 954 \\
\hline 4 & 2 & 157.1 & 146.9 & 7394 & 3930 & 1411 & 1832 \\
\hline 5 & 1 & 144.6 & 143.0 & 7287 & 3834 & 2025 & 2665 \\
\hline 6 & 2 & 123.4 & 68.8 & 6930 & 3573 & 3400 & 5112 \\
\hline 7 & 2 & 101.9 & 112.5 & 6795 & 3471 & 3846 & 5777 \\
\hline 8 & 2 & 101.7 & 101.3 & 6754 & 3445 & 3938 & 5920 \\
\hline 9 & 2 & 100.5 & 100.3 & 6736 & 3432 & 3988 & 5997 \\
\hline
\end{tabular}

${ }^{\dagger}$ Problem Specification: Tensile Gap $E_{M}=100-20-5-1$-etc.

${ }^{*} R=3.20$ in., $Z=0.37$ in.

${ }^{*} R=3.28$ in., $Z=0.75$ in. 
THE JOHNS HOPKINS UNIVERSITY APPLIED PHYSICS LABORATORY

LAUREI MARYLAND

large difference in stress between iterations 1 and 9 for element 184

illustrates the importance of proper contact modeling.

The need for a modification of the basic gap closure algorithm is illustrated in Fig. 19 for a particular hypothetical gap element. The figure shows the stress-strain 1ocation (where $\epsilon_{M_{K}}<-100 \%$ ) after the Kth iteration. Employing invariance the gap modulus is increased to $\mathrm{E}_{\mathrm{K}+1}$ and the gap strain $\varepsilon_{\mathrm{M}+1}$ is increased incrementally toward a closure value of $-100 \%$. Proceeding in this manner, convergence should eventually be achieved. To accelerate convergence an extrapolated value, $\mathrm{E}_{\mathrm{X}_{\mathrm{K}+2}}$, can be determined based on a linear curve fit through $\epsilon_{M_{K}}$ and $\epsilon_{M_{K+1}}$. Then for the $(K+2)$ nd iteration, $\overline{\mathrm{E}}_{\mathrm{K}+2}$

obtained from

$$
\overline{\mathrm{E}}_{\mathrm{K}+2}=(1-\mathrm{f}) \cdot \mathrm{E}_{\mathrm{K}+2}+\mathrm{f} \cdot \mathrm{E}_{\mathrm{X}+2}
$$

is used where $f$ is a specified fraction satisfying $0 \leq f<1$. The solution at iteration $(K+2)$ will then lie on the line with slope $\overline{\mathrm{E}}_{\mathrm{K}+2}$. The extrapolation procedure is used with two qualifications:

(1) The tensile gap moduli are at the smallest value in the schedule -only gap compression is controlling convergence, and

(2) Gap strain $\varepsilon_{\mathrm{M}_{\mathrm{K}+1}}>\epsilon_{\mathrm{M}_{\mathrm{K}}}$ for all gaps in compression with

$\epsilon_{\mathrm{M}_{\mathrm{K}+1}}<-100 \%$-- otherwise extrapolation could be extremely

disturbing to the convergence process.

Iteration 6 in Table $V$ is apparently the result of the weighted extrapolation using iterations 4 and 5 in which $f=0.5$. 


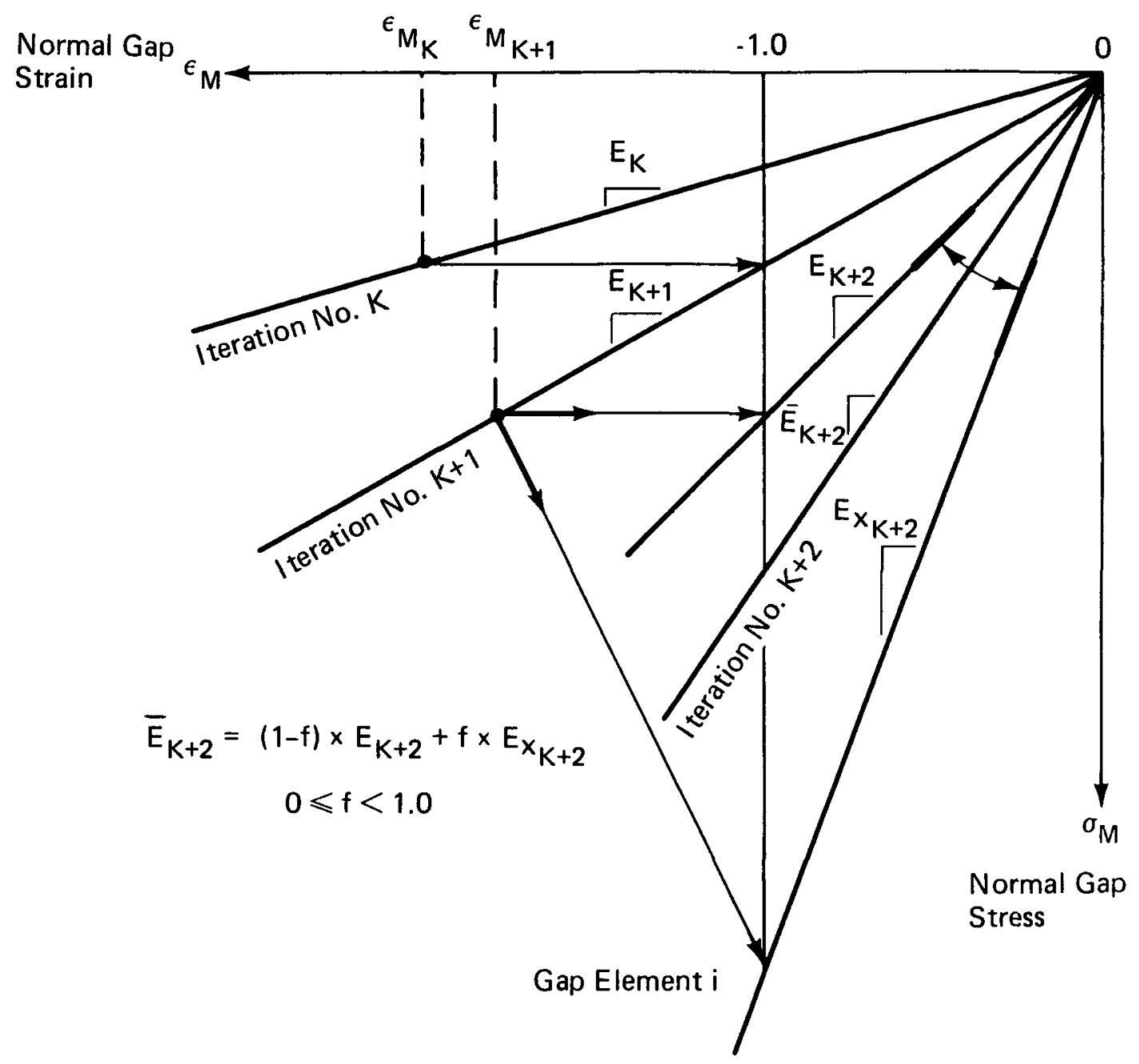

Fig. 19 Stress Invariance with Extrapolation for Gap Closure 
THE JOHNS HOPKINS UNIVEASITY APPLIED PHYSICS LABORATORY

Laupel marylano

\section{CONCLUDING REMARKS}

A numerical procedure has been developed to analyze structural contact problems. The procedure, which has been implemented in the SAASGAPS program, has not been tested extensively; however, results obtained for three sample problems seem to indicate that the procedure works well for simple contact situations. The two MHW-RTG heat shield problems involve more complicated contact conditions. For these problems, some of the repugnant reatures associated with nonlinear analyses have surfaced. The behavior of the algorithm appears to be dependent on the geometry of the component structures, and on the magnitude and type of loading causing the contact. Nonetheless, the program has proven invaluable for analysis of contact problems of interest to the Nuclear Safety Program at APL.

The behavior of the algorithm on other types of contact and interference problems has yet to be evaluated. In this regard, a classica1 Hertz-type contact problem will be examined as an additional verification of the method. The SAASGAPS procedure will be used in subsequent stress analyses of MHW-RTG heat shield designs. Finally, since the current version of the program is limited to frictionless contact, modifications for a gap friction-element are planned so that problems involving sliding contact can be analyzed. 
(1) J. G. Crose and R. M. Jones, "SAAS III - Finite Element Analysis of Axisymetric and Plane Solids with Different Orthotropic, Temperature Dependent Material Properties in Tension and Compression", Air Force Report No. SAMSO-TR-71-103, June 22, 1971.

(2) J. L. Lubkin, "Contact Problems", Section 42 of the Handbook of Engineering Mechanics, W. Flügge, (ed), McGraw-Hi11 Book Co., Inc., 1962.

(3) T. F. Conry and A. Seineg, "A Mathematical Programming Method for Design of Elastic Bodies in Contact", Trans. ASME, Journal Applied Mechanics, June 1971, pp. 387-392.

(4) K. P. Singh and B. Paul, "Numerical Solution of Non-Hertzian Elastic Contact Problems", Trans. ASME, Journal Applied Mechanics, June 1974, pp. $484-490$.

(5) T. S. Arora and J. S. Arora, "Optimization of Surface Contours for Elastic Bodies in Contact", Iowa University Report AC-CR-75-005 Prepared for U. S. Army Armament Command, May 1975 (AD-A010-405).

(6) J. B. Newman, "Analysis of Problems Involving Nonlinear Boundary Conditions and Nonlinear Material Properties", in Numerical Solution of Nonlinear Structural Problems, ASME Publication, Nov. 1973.

(7) E. A. Wilson and B. Parsons, "Finite Element Analysis of Elastic Contact Problems Using Differential Displacements", Int. Journal for Numerical Methods in Engineering, Vo1. 2, 1970, pp. 387-395.

(8) S. K. Chan and I. S. Tuba, "A Finite Element Method for Contact Problems of Solid Bodies, Parts I and II", Int. Journal of Mechanical Sciences, Vo1. 13, 1971, pp. 615-625. 
(9) T. Tsuta and S. Yamaji, "Finite Element Analysis of Contact Problem", in Theory and Practice in Finite Element Structural Analysis, Y. Yamada and R. H. Gallagher (eds.), University of Tokyo Press, 1973.

(10) A. Francavilla and 0. C. Zienkiewicz, "A Note on Numerical Computation of Elastic Contact Problems", Int. Journal for Numerical Methods in Engineering, Vo1. 9, 1975, pp. 913-924.

(11) A. Mendelson, Plasticity: Theory and Application, The MacMillan Company, New York, 1968.

(12) R. J. Roark, Formulas for Stress and Strain, McGraw-Hi11 Book Co., Fourth Edition, 1965.

(13) R. H. Gallagher, Finite Element Analysis, Prentice-Hall, Inc., New Jersey, 1975.

(14) J. T. Stadter and R. 0. Weiss, "CøNPLøT - A General Purpose Contour Plotting Program", Applied Physics Laboratory/The Johns Hopkins University, ANSP-M-9, June, 1974. 
APPENDIX A

SAASGAPS Input Instructions

Since SAASGAPS is basically an extended version of the SAAS III program (Ref. 1), a familiarity with the data preparation for the original program will be assumed. The instructions described below pertain only to those additional input requirements necessary for a gap closure problem. The potential user is urged to consult Appendix F of Ref. 1 before proceeding. JOB CONTROL CARD

This card is as described on p. F-3 of Ref. 1 except that the number of different materials (columns 44-45) should be equal to one more than the actual number of materials in the problem. The extra material specification is for gap properties.

\section{ELEMENT CARDS}

These cards are prepared as described in Ref. 1. Since $E_{M}$ for gap elements is the modulus of elasticity in the direction of contact, its direction must be defined. This is accomplished by specifying the material principal property inclination angle as the direction of gap closure or contract, according to the format given in Ref. 1.

\section{MATERIAL PROPERTY INFORMATION}

The actual material properties must be specified first according to the format set forth in Ref. 1. The last and largest material identification is reserved for gap properties. With the ISO parameter set to 0 , the initial value of $E_{M}$ in the tensile reduction schedule is specified. The remaining moduli 
and Poisson's ratio are unimportant since the transverse moduli are set to tensile values in the schedule (to be described subsequently) and all Poisson's ratios are set to zero. A zero coefficient of thermal expansion should be specified. In addition to $E_{M}$, the second key parameter in the definition of a gap element is PEMR, the ratio of effective plastic to elastic modulus. A negative value must be used since the sign of PEMR is tested by the program as a means of flagging a gap element.

\section{GAP CLOSURE INFORMATION}

If $\mathrm{PEMR}<0$ then immediately following the material property information group, a gap control card and a gap tensile modulus reduction schedule should be given.

\section{a. Gap Contro1 Card}

Format (2I5, F10.0)

Columns 1-5 number of subsequent tensile gap moduli, NøPCEO

$6-10$ not used

10-20 weighting factor used in the linear extrapolation for compressed gaps, XFACT $(0 \leq \mathrm{XFACT}<1)($ see p. 46$)$

b. Tensile Modulus Reduction Schedule

Format $(8 \mathrm{~F} 10.0)$

Columns 1-10 etc. A sequence of fractions, PCEO which when multiplied with the initial gap modulus $E_{M}$ gives subsequent tensile moduli. There should be NØPCEO of these. The smallest fraction should be such that PCEO - $E_{M}=1$ psi (for example). If more than 8 values are to be specified the additional ones are on successive cards. 
THE JOHNS HOPKINS UNIVERSITY APPLIED PHYSICS LABORATORY

LaURel MaRYLAND

When a gap closure problem is being solved, the number of non-linear approximations (p. F-3 of Ref. 1) will be set by the program to a value of $(\mathrm{N} \emptyset \mathrm{PCEO}+1)$. This completes the input specifications for gap problems.

The original SAAS program allows the user to stop after mesh plotting (IST $\varnothing \mathrm{P}=1, \mathrm{Co1} .10$ on the Job Control Card) or before contour plotting $($ IST $\emptyset \mathrm{P}=2)$. In the latter case, by resetting the start parameter (ISTART $=2$, Col. 5 on the Job Control Card), contour plots can be made from a data tape without having to rerun the problem. However, a computational restart cannot be specified with the SAAS program.

In developing the SAASGAPS version, it was decided that a computational restart was absolutely a necessity to avoid the expense of problem reruns associated with premature termination of the iterative process. The last iteration of a particular computer run $c$ an be saved on FøRTRAN Unit 10.

\section{COMPUTATIONAL RESTART}

When restarting with a data set saved from a previous computer run, the value of ISTART is set equal to 3 . Using the data deck assembled for the previous run, a card with READ ( $c 01.1-4$ ) should be placed before the GAP CLØSURE INFØRMATION cards. The program will ignore all data cards except those following the READ card. Since the computations to be performed are a continuation of those contained in the data file, the new PCEO values must be referenced to the initial gap modulus specified when the problem was first run. Upon reading the GAP CL $Q S U R E$ INF $Q R M A T I \emptyset N$, the computations resume with a printout of the last solution for the element stresses and strains. Then iteration 2 will be the first iteration of the restart. 
In addition to the usual SAAS program output, immediately following the material property data printout, a summary of gap input data is given. However, instead of the fractions PCEO, the actual tensile gap modulus schedule is listed in psi values.

The output of the original SAAS program contains no information about which elements were not meeting the convergence requirements. Therefore, as an aid to monitoring the progress of the iteration process, two columns headed "YIELD?" and "N-L/CØNV?" have been added to the element stress output 1isting. A column for "GAP-C $\emptyset N V$ ?" is given in the element strain output. For the YIELD? column only a "YES" is printed for those elements above yield stress while in the $\mathrm{N}-\mathrm{L} / \mathrm{C} \emptyset \mathrm{NV}$ column only a "NO" is printed to indicate lack of convergence for yielded elements. In a similar manner a "NO" in the GAP-C $\emptyset \mathrm{NV}$ ? column indicates those gap elements which do not meet the gap element convergence tests.

Following the element strain output are printed the number of fully closed gap elements, the average closure, and the number of non-converged gap elements. 
THE JOHNS HOPKINS UNIVERSITY APPLIED PHYSICS LABORATORY

LAUREL MAAYLAND

INI TIAL DISTRIBUTTON EXTERNAL TO THE APPLIED PHYSICS IABORATORY

\begin{tabular}{|c|c|c|c|}
\hline ORGANIZATI ON & LOCATION & A TTENTI ON & $\begin{array}{l}\text { NO. OF } \\
\text { COPIES }\end{array}$ \\
\hline $\begin{array}{r}\text { Energy Research and Development } \\
\text { Administration }\end{array}$ & Germantown, Md. & $\begin{array}{l}\text { A. L. Mowery } \\
\text { G. P. Dix } \\
\text { T. J. Dobry } \\
\text { N. Goldenberg } \\
\text { H. Jaffe } \\
\text { J. J. Lombardo } \\
\text { W. C. Remini } \\
\text { C. Neil Sherman }\end{array}$ & $\begin{array}{l}1 \\
1 \\
1 \\
1 \\
1 \\
1 \\
1 \\
1\end{array}$ \\
\hline Air Force Weapons Laboratory & Albuquerque, N.M. & Lt. W. Holtzscheiter & 1 \\
\hline NASA/Ames & Moffet Field, CA. & W. Pitts & 1 \\
\hline NASA/Langley & Hamp ton, Va. & G. D. Walberg & 1 \\
\hline Los Alamos Scientific Laboratory & Los Alamos, N.M. & R. N. R. Mulford & 1 \\
\hline Oak Ridge National Laboratory & Oak Ridge, Tenn. & R. G. Donnelly & 1 \\
\hline $\begin{array}{r}\text { Oak Ridge Technical Information } \\
\text { Center }\end{array}$ & Oak Ridge, Tenn. & R. L. Shannon & 1 \\
\hline Aerospace Corporation & Los Angeles, CA. & C. Melfi & 1 \\
\hline AVCO Systems Division & Wilming ton, Mass. & R. Ryan & 1 \\
\hline General Electric Co. & King of Prussia, Pa. & $\begin{array}{l}\text { R. Wiley } \\
\text { C. T. Bradshaw }\end{array}$ & $\begin{array}{l}1 \\
1\end{array}$ \\
\hline Donald W. Douglas Laboratory & Richland, Wash. & J. D. Watrous & 1 \\
\hline Fairchild Industries & Germantown, Md. & H. P. Kling & 1 \\
\hline TRW Systems, Inc. & Redondo Beach, CA. & J. M. Be 11 & 1 \\
\hline Westinghouse Electric Corp. & Pittsburgh, $\mathrm{Pa}$. & W. G. Parker & 1 \\
\hline Teledyne Isotopes & Timonium, Md. & $\begin{array}{l}\text { D. C. Anderson } \\
\text { D. Owings }\end{array}$ & $\begin{array}{l}1 \\
1\end{array}$ \\
\hline
\end{tabular}

